\title{
Floral development in the Metrosideros group (Myrtaceae) with special emphasis on the androecium
}

\author{
D.A. Orlovich, A.N. Drinnan and P.Y. Ladiges
}

\begin{abstract}
Orlovich, D.A., Drinnan, A.N. and Ladiges, P.Y. (School of Botany, The University of Melbourne, Parkville, Victoria 3052, Australia) 1996. Floral development in the Metrosideros group (Myrtaceae) with special emphasis on the androecium. Telopea 6(4): 689-719. The floral development of eleven taxa in the informal 'Metrosideros group' (Myrtaceae) is described. Two general patterns of androecial development are identified. The multistaminate fascicles of Lophostemon confertus, L. suaveolens, L. lactifluus, Welchiodendron longivalve and Tristaniopsis laurina develop from stamen primordia initiated on antepetalous pre-staminal bulges. In Xanthostemon oppositifolius, X. verticillatus and Lysicarpus angustifolius, which have a complete ring of unfused stamens, often with more stamens in the antepetalous region, pre-staminal bulges do not develop prior to stamen initiation; stamen primordia are initiated directly on the floral tube. Differential hypanthial expansion results in the spreading-out of antesepalous stamens whilst antepetalous stamens remain clustered in front of the petals. Metrosideros collina var. villosa, Tristania neriffolia and Thaleropia queenslandica have fewer stamens, which develop on either small pre-staminal bulges $(M$. collina $)$ or on the flank of the invaginated floral apex. Staminal arrangement in all the taxa studied is a result of the interaction between the timing of androecial initiation and the available space on the hypanthium.
\end{abstract}

\section{Introduction}

The family Myrtaceae is large, diverse and widely distributed in the southern hemisphere, where it is a prominent component of the Australian flora, including 75 native genera, of which 55 are endemic. Based on morphological characters, Johnson and Briggs (1984) presented a phylogenetic analysis of Myrtaceae as part of a broader study of the order Myrtales. Floral characters included those of the androecium, which shows a variety of form in mature flowers. Within Myrtaceae, stamens vary in number, colour, length, position, whether they form clusters or not, and whether stamen filaments are united or free.

Schmid (1980) discussed staminal placement in Myrtaceae in terms of diplostemony, haplostemony, obdiplostemony, and obhaplostemony. Johnson and Briggs (1984) argued for a more interpretative, rather than wholly descriptive approach, and presented an hypothetical scenario of sequences of androecial evolution. They suggested that the 'origin of the family more or less coincides with the proliferation of stamen initials within each of the ten primordia corresponding to an earlier ancestral 5-merous, 2 whorled condition' (p. 739). They concluded, thus, that the original androecial condition in Myrtales was diplostemonous (10 subequal stamens), but that, in Myrtaceae, this gave way first to obdiplostemony (10 stamens with smaller stamens opposite sepals) and then to 10 stamen fascicles, the antesepalous fascicles being small. From this they derived the range of conditions observed in mature flowers, including only antepetalous (obhaplostemonous) stamens or fascicles, rings of stamens, or reduction or suppression of stamens (Johnson and Briggs 1984, Fig. 8, p. 740).

Although variation in form of mature myrtaceous flowers is relatively well known, developmental studies are needed for character definition (assessment of homology) and as evidence for character polarity (transformation from plesiomorphic to 
apomorphic conditions) for phylogenetic analysis. Studies by Mayr (1969) and Bunniger (1972) of floral development in the order Myrtales provide a foundation on which to base new detailed studies, although neither worker was able to use scanning electron microscopy and results were presented as line drawings of sections. Our recent work on floral development of Angophora and Eucalyptus (Drinnan and Ladiges 1988, 1989a,b,c, 1991a,b) has allowed new interpretations of floral characters in these myrtaceous taxa and highlights that seemingly similar conditions in mature flowers can result from different developmental processes and are not therefore homologous (for example, stamen bundling in eudesmioid eucalypts is not equivalent to that seen in Eucalyptus microcorys, Drinnan and Ladiges 1991b).

The present paper is the first in our series of floral development in Myrtaceae. It deals with the Metrosideros group of Briggs and Johnson (1979), which includes suballiances Kania, Metrosideros, Xanthostemon and Lophostemon pro parte (Johnson and Briggs 1984). Androecial development is described for eleven taxa (Table 1), which vary from having stamens in distinct, petal-opposed fascicles with strongly united filaments (Lophostemon and Tristaniopsis) to having a ring of free stamens (Metrosideros and Xanthostemon).

Table 1. Collection information for the taxa examined

Lophostemon confertus

Lophostemon lactifluus

Lophostemon suaveolens

Lysicarpus angustifolius

Metrosideros collina var. villosa

Thaleropia queenslandica

Tristania neriifolia

Tristaniopsis laurina

Welchiodendron longivalve

Xanthostemon oppositifolius

Xanthostemon verticillatus
Victoria: On lawn $S$ of Old Commerce Building, Melb. Univ. (cultivated), Drinnan AND 481, 25 Nov 1986; Orlovich DAO 187, 1 Dec 1993, DAO 195 \& Vadala, 20 Dec 1993 (MELU).

Northern Territory: Mary R., Arnhem Highway, Wilson \& Waterhouse UNSW 4016, 11 July 1974 (NSW, UNSW).

Queensland: $6.5 \mathrm{~km}$ SE. Kuranda, Waterhouse \& Quinn UNSW 1440, 22 Aug 1970 (UNSW); Fitzroy Island, off Cairns, Rozefelds DAO 233, 3 July 1994 (MELU).

Queensland: Cherwell Range, Wilson PGW 569 \& Rowe, 7 Sep 1990 (NSW, BRI, ASU).

New South Wales: Royal Botanic Gardens, Sydney, near Conservatorium gate (cultivated, accession \#17682), Orlovich DAO 44 \& Wilson, 5 May 1993 (MELU).

Victoria: The University of Melbourne in pot near School of Botany glasshouses (cultivated), Orlovich DAO 199 \& Vadala, 8 Mar 1994 (MELU).

New South Wales: Royal Botanic Gardens, Sydney (cultivated), Orlovich DAO 169 \& Wilson, 4 Nov 1993 (MELU).

Victoria: Royal Botanic Gardens, Melbourne (cultivated), Neish AND 561, 30 Nov 1992, AND 562, 4 Jan 1993 (MELU).

Queensland: collected near Lockerbie (10 $\left.47^{\prime} \mathrm{S}, 147^{\circ} 27^{\prime} \mathrm{E}\right)$, altitude $20 \mathrm{~m}$, Hyland 11042, 22 May 1981 (QRS); Cape York Peninsula, within $150 \mathrm{~m}$ of Pajinka Wilderness Lodge via Bamaga, Tree no. 1 from helipad track, Roberts DAO 237, 4 April 1995 (MELU).

New South Wales: Royal Botanic Gardens Sydney, Mount Annan garden (cultivated, accession \# 865650), Orlovich DAO 221 , 12 May 1994 (MELU).

New South Wales: Royal Botanic Gardens Sydney, Mount Annan garden (cultivated, accession \# 923070), Orlovich DAO 36 , 4 May 1993 (MELU). 


\section{Materials and Methods}

The eleven taxa studied are listed in Table 1. Fresh specimens were fixed in either formalin-acetic acid-alcohol (FAA) or $70 \%$ ethanol. For scanning electron microscopy, flower buds were dehydrated in $100 \%$ ethanol and stained with $0.5 \%$ acid fuschin in 95\% ethanol for a minimum of 24 hours to aid visibility during dissection. Buds were dissected in $100 \%$ ethanol and critical point dried. Mounted specimens were coated with gold and examined with a scanning electron microscope (JEOL JSM 840 ). Buds fixed in FAA or $70 \%$ ethanol were prepared for light microscopy by dehydration in ethanol followed by embedding in resin (LR White, London Resin Co.). Sections $1.0 \mu \mathrm{m}$ thick were stained with $0.5 \%$ toluidine blue $\mathrm{O}$ in $0.1 \% \mathrm{Na}_{2} \mathrm{CO}_{3}$ (O'Brien and McCully 1981). Flowers were cleared in 10 or $15 \% \mathrm{NaOH}$-basic fuschin as described in $\mathrm{O}^{\prime}$ Brien and McCully (1981).

\section{Results}

\section{Lophostemon confertus (R. Br.) Peter G. Wilson \& J.T. Waterhouse}

Mature flowers of $L$. confertus have five sepals, five petals and five antepetalous stamen fascicles with approximately 70 filaments each (Fig. 1). The first two sepal primordia are initiated asynchronously in a decussate position relative to the bud scales (Fig. 2a). Subsequent sepals are initiated in a spiral pattern. The floral apex invaginates and the petal primordia are initiated on the flank of the developing concave floral apex (Fig. 2b), continuing the spiral pattern initiated in the sepals. Following petal initiation, a prestaminal bulge (PSB) develops in the region centripetal to each petal primordium (Fig. $2 c, 3 a)$ and a shallow vertical, groove-like depression develops in each bulge (Fig. 2d). Each antepetalous PSB remains distinct from those adjacent to it, which are different sizes due to asynchronous initiation (Fig. 2e). Stamens form on the PSB. The initiation of stamen primordia is bilaterally symmetrical around the shallow depression (Fig. 2f). The first-formed stamens are initiated in the centre of the PSB and along its top edge; subsequent stamens are initiated along both sides of the PSB (Fig. $2 \mathrm{~g}$ ) and always on the adaxial surface. The depression forms a notch in the top of the fascicle (Fig. $2 \mathrm{~h}$ ) and continues along its abaxial side (Fig. 2i). As the flower bud develops, the abaxial side of each PSB elongates to form a staminal fascicle that is bifid (Fig. 3b-d). Free stamens arise only from the adaxial side of the fascicle. The oldest stamens are those situated along the axial midline of the fascicle and younger stamens are positioned along the edges. Vascular traces of individual stamens remain distinct for the full length of the fascicle (Fig. 3e).

\section{Lophostemon suaveolens (Soland. ex Gaertn.) Peter G. Wilson E.J.T. Waterhouse}

Mature flowers of $L$. suaveolens (Fig. 4a) have five sepals, five petals and five antepetalous stamen fascicles. The fascicles, like those of $L$. confertus, are bifid (Fig. 4b). The first two sepals are initiated asynchronously in a position decussate to the two floral bracts (Fig. 5a). A third sepal is initiated in space on the enlarging floral apex (Fig. 5b). At about the same time as the initiation of the third sepal, the floral apex invaginates (Fig. 5c). Subsequent sepals are initiated in a spiral sequence (Fig. 5d). The first petal primordium is initiated in the same sequence as the sepals (Fig. 5d) and is followed by the asynchronous initiation of the remaining four (Fig. 5e). As the petal primordia develop, the region directly centripetal to each petal primordium enlarges, forming a pre-staminal bulge (PSB) (Fig. 5f). The PSBs develop asynchronously (Fig. $5 \mathrm{~g}$ ) corresponding to the size of the associated petal. A vertical groove develops in each PSB (Fig. 5h) and stamen primordia are initiated symmetrically around this groove (Fig. 5i). Stamens are first initiated along the top 
of the PSB (Fig. 5i) and later at the outer edges (Fig. 5j). The PSB and free filaments elongate to form the stamen fascicle. The groove in the PSB manifests as a cleavage in the bifid fascicle (Fig. 5k).

\section{Lophostemon lactifluus (F. Muell.) Peter G. Wilson E J.T. Waterhouse}

Flowers of L. lactifluus have five antepetalous stamen fascicles (Fig. 6a). Unlike L. confertus and $L$. suaveolens, the fascicles are not obviously bifid (Fig. 6b) in the limited material available for this species. The petal primordia are initiated between the sepals on the flank of the invaginating floral tube (Fig. 7a). Stamens are initiated on a PSB opposite each petal (Fig. 7b). The first stamens are initiated in the centre of the PSB and later ones

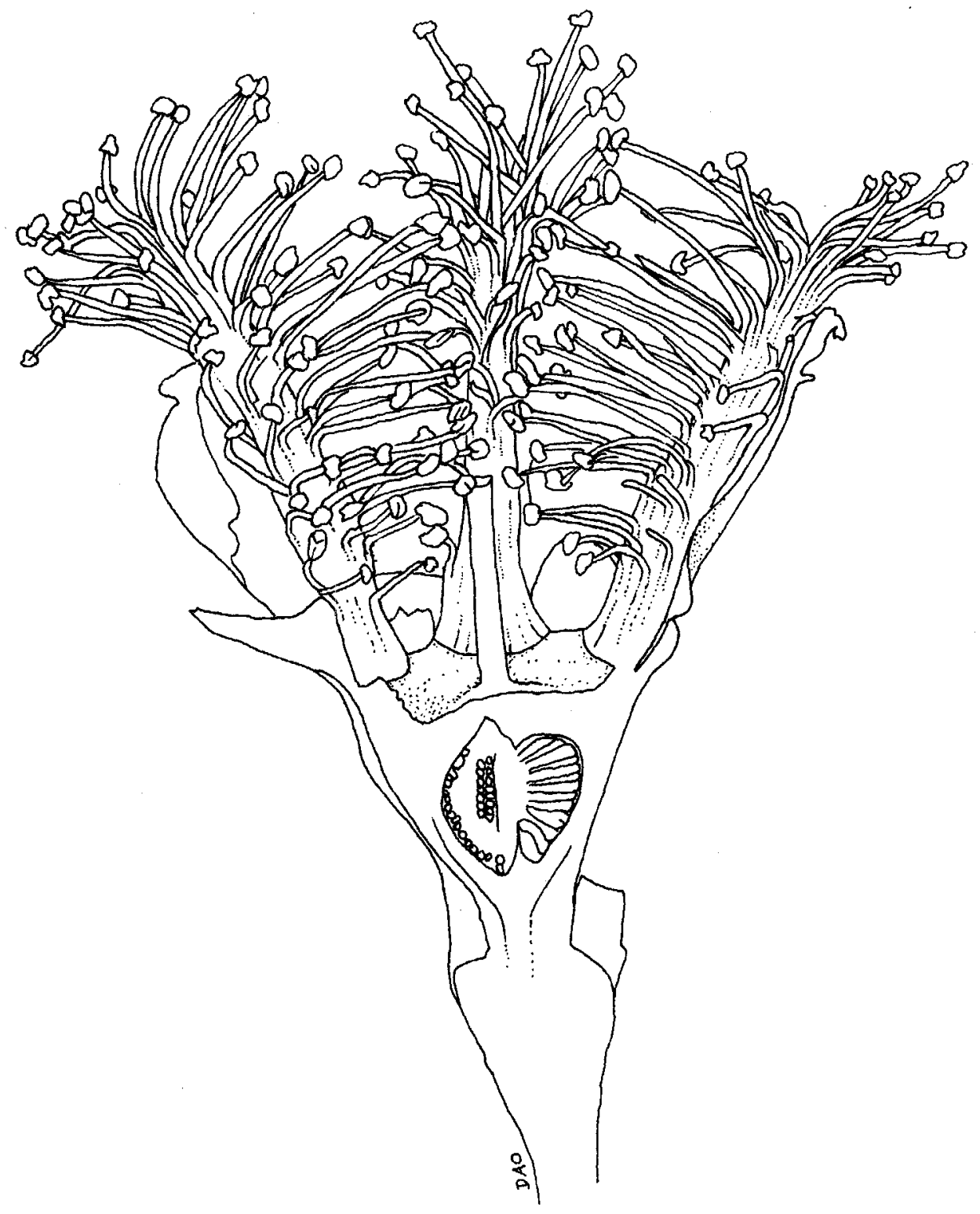

Fig. 1. Lophostemon confertus. Mature half flower. $(\times 5.7)$. (from $D A O 195)$. 
at the outer edges (Fig. 7c). The stamen bundles thus formed are clustered opposite each petal (Fig. $7 \mathrm{~d}$ ). The region of filament fusion in each bundle elongates (Fig. 7e) to produce a fascicle in the mature flower. In the mature bud, there is no obvious cleavage in the fascicle, however, there is a small gap at the centre of the tip of each fascicle indicating that stamens are not initiated first in this central position. Fascicles are situated on the rim of the hypanthium in the mature flower (Fig. 7f) and have the same texture and colour as filament tissue rather than tissue derived from the hypanthium.

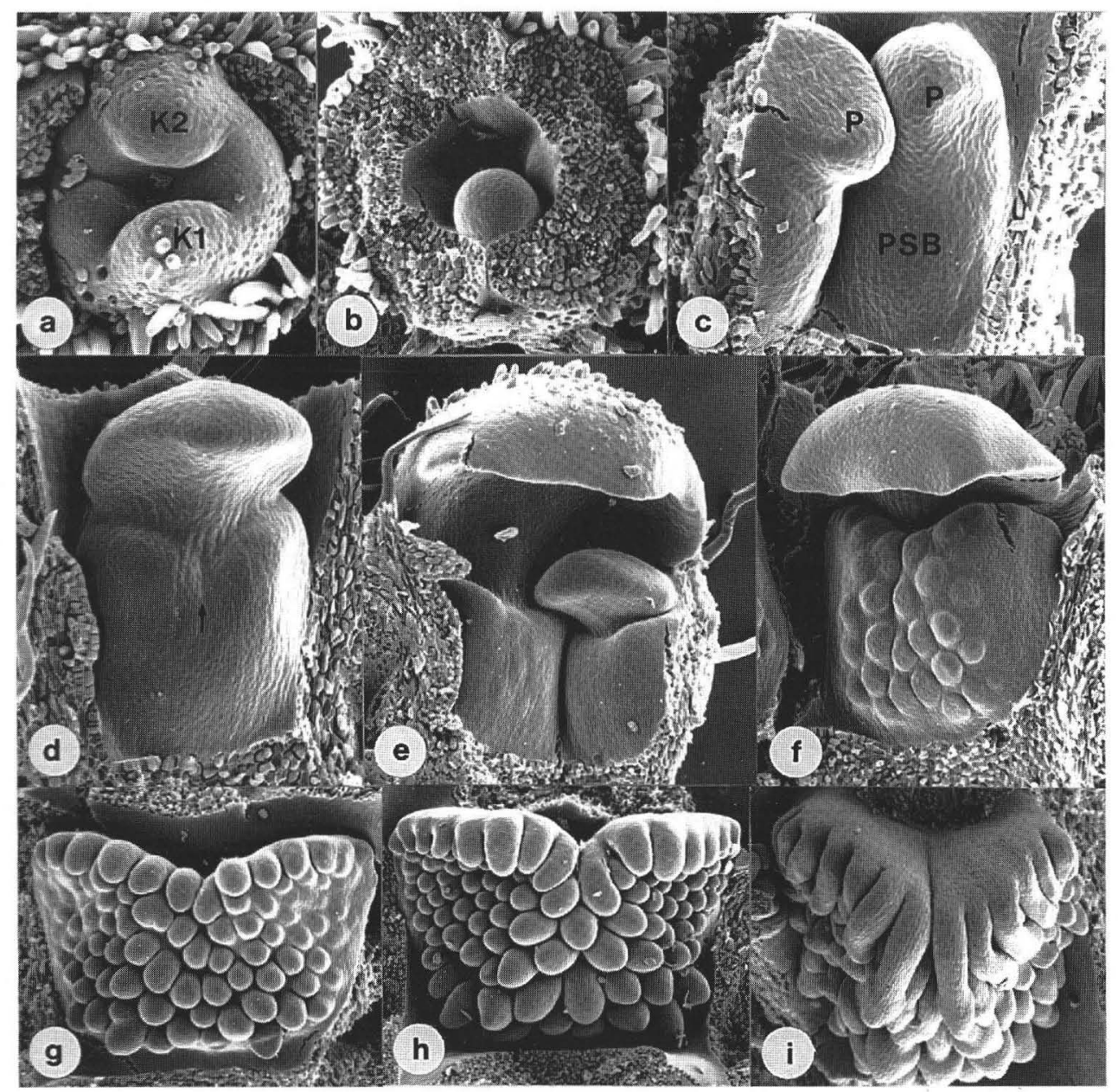

Fig. 2. Floral development of Lophostemon confertus. a, young flower bud showing two large (K1, K2) and three smaller sepal primordia. Two floral bracts (bud scales) have been removed $(\times 145)$; b, bud with sepals removed to show sequential initiation of the first few petal primordia $(\times 120)$; c, part of a flower bud showing two petal primordia (P). In front of each primordium is a swollen region, the pre-staminal bulge (PSB), upon which the stamens will develop $(\times 180)$; $d$, the petal primordium is clearly differentiated from the PSB, which has developed a shallow, vertical groove (arrow) ( $\times 150$ ); e, two adjacent petals and PSB. The left primordium is much larger than that on the right. Small swellings on the PSB beneath the left primordium are individual stamen primordia; no stamen primordia have developed on the PSB on the right $(\times 95) ; \mathbf{f}-\mathbf{i}$, initiation and development of stamen primordia on the PSB. Stamen primordia are first initiated along the lower central region and then along the top of the PSB. The groove extends back along the abaxial side of the fascicle (f $\times 110 ; \mathbf{g} \times 90 ; \mathbf{h} \times 68 ; \mathbf{i} \times 70$ ). (a-h from $A N D$ 481; i from $D A O$ 187). 


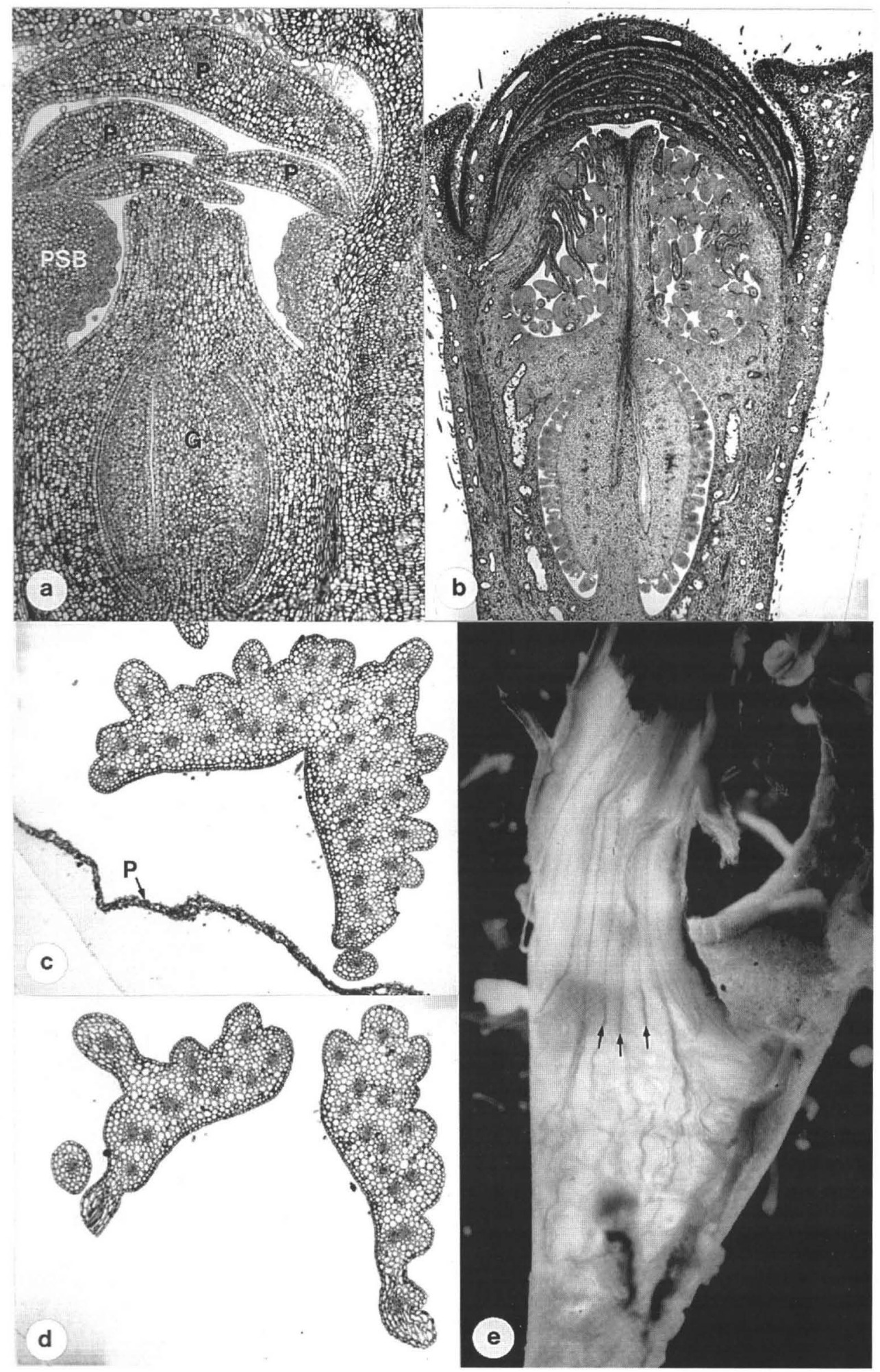


Fig. 3. (left) Lophostemon confertus. a, median longitudinal section through a young flower bud at the stage of stamen initiation. By this stage the gynoecium $(\mathrm{G})$ is well developed. $\mathrm{K}-$ sepal, P - petal, PSB - pre-staminal bulge $(\times 91)$; b, median longitudinal section through a mature bud ( $\times 19.5)$; c, transverse section near the base of a single stamen fascicle after anthesis. Stamen filaments diverge from the inner side of the fascicle only. $\mathrm{P}-$ petal $(\times 37)$; $d$, section through the upper half of the same fascicle as c. The fascicle is split into two at this level. The epidermis is continuous around each half, indicating that the split is not a result of tearing during filament extension or specimen handling $(\times 37)$; e, cleared stamen fascicle showing individual filament vascular traces (arrows) $(\times 23)$. (a,b from AND 481; c-e from DAO 195).

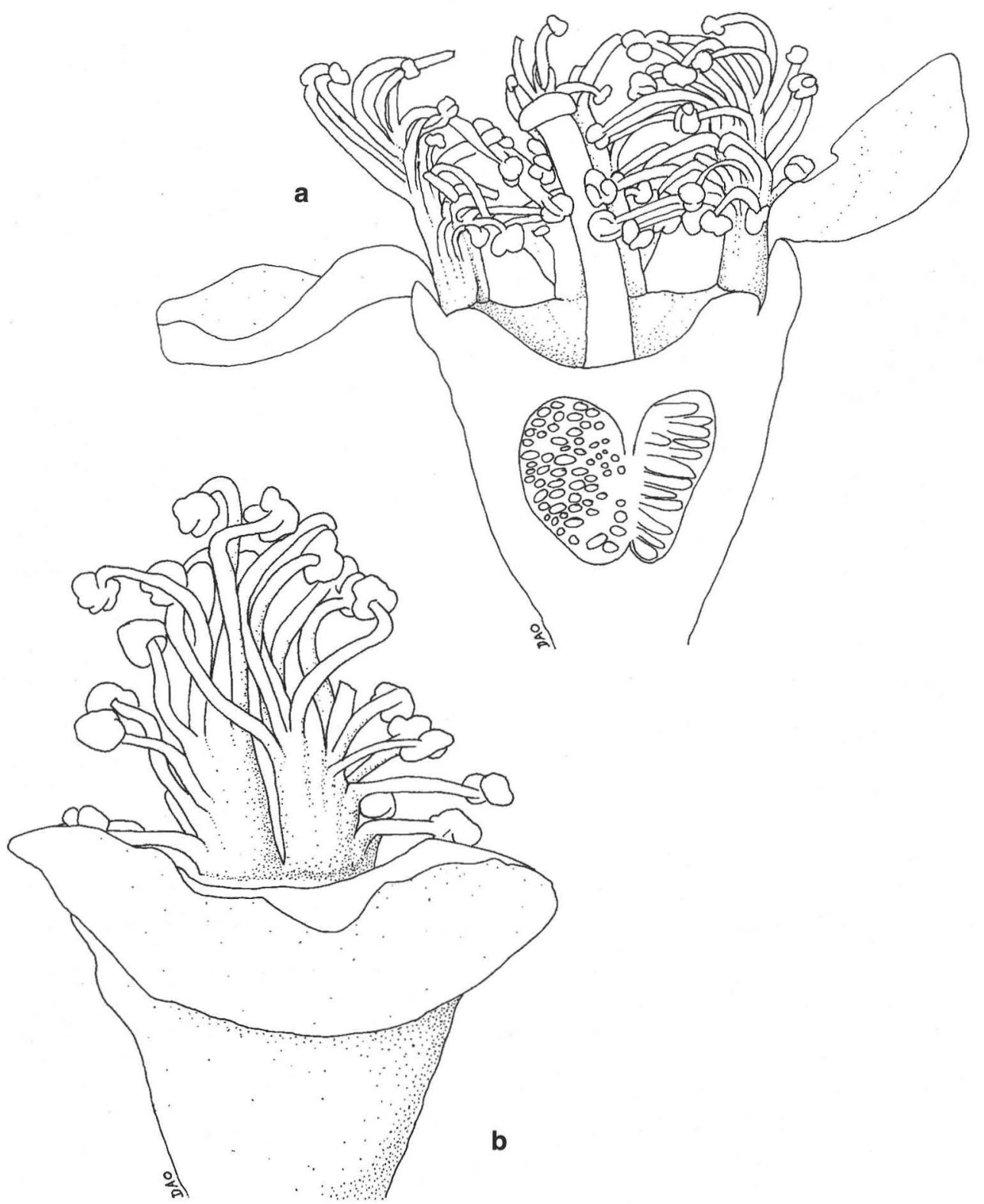

Fig. 4. Lophostemon suaveolens. a, mature half flower $(\times 11.6)$; b, stamen fascicle drawn from the back to illustrate the bifid nature of the fascicle ( $\times 18.5)$. (from DAO 233). 


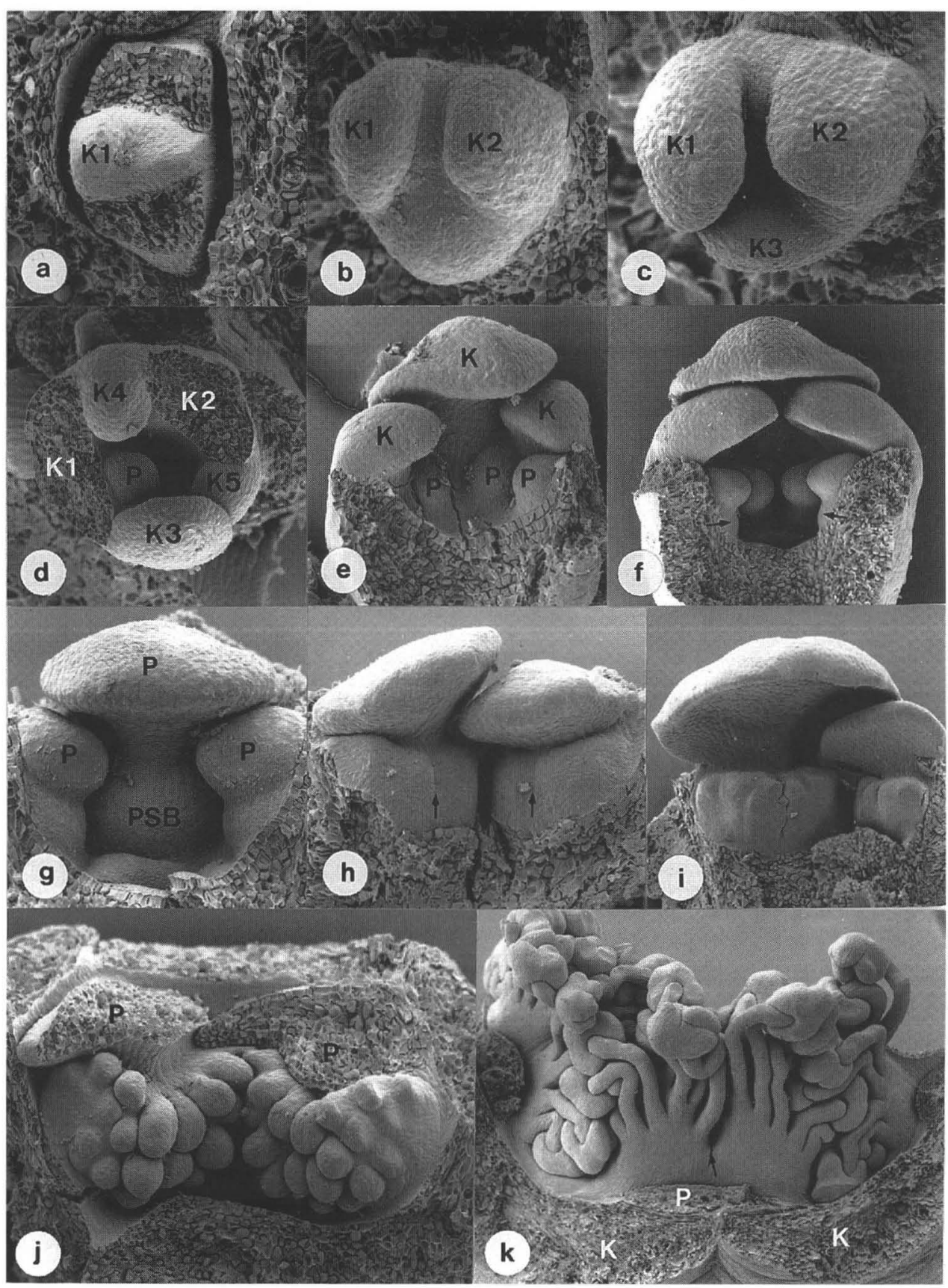


Fig. 5. (left) Floral development in Lophostemon suaveolens. a, very small flower primordium. Two bracts have been removed to show the first sepal primordium $(K)(\times 170)$; b, flower bud with two sepal primordia $(\mathrm{K} 1-2)(\times 250)$; c, flower bud with three sepal primordia $(\mathrm{K} 1-3)(\times 250)$; d, flower bud with five sepal primordia arranged in a spiral pattern. Two sepals have been removed (K1-2) to show the other three sepal primordia (K3-5) and the first petal primordium (P). The floral apex is beginning to invaginate $(\times 140)$; $\mathrm{e}$, half flower bud with two sepals removed to show developing petal primordia (P). K - sepal ( $\times 135)$; f, flower bud with three sepal and four petal primordia. A small PSB is visible directly in front of each petal primordium (arrows) $(\times 90) ; \mathrm{g}$, three petal primordia $(\mathrm{P})$ with a PSB in front of each one. There is a distinct difference in size between adjacent petal primordia $(\times 190)$; $\mathbf{h}$, two petal primordia with a PSB in front of each one. A vertical groove is visible on each PSB at this stage (arrows) $(\times 160)$; i, two petal primordia with a PSB in front of each one. Stamen primordia are visible along the upper edge of each PSB $(\times 90)$; $j$, part of a flower bud after initiation of most stamen primordia. Two petals have been removed $(\mathrm{P})$. The oldest stamens are those situated at the upper central region of the PSB. There are small stamen primordia at the edges of each PSB $(\times 120)$; k, mature flower bud viewed from the outside of the flower shortly before anthesis. Sepals (K) and petals $(\mathrm{P})$ have been removed to expose a stamen fascicle. The fascicle is bifid, the central split (arrow) corresponding in position to the notch on the PSB in younger buds $(\times 40)$. (from DAO 233).

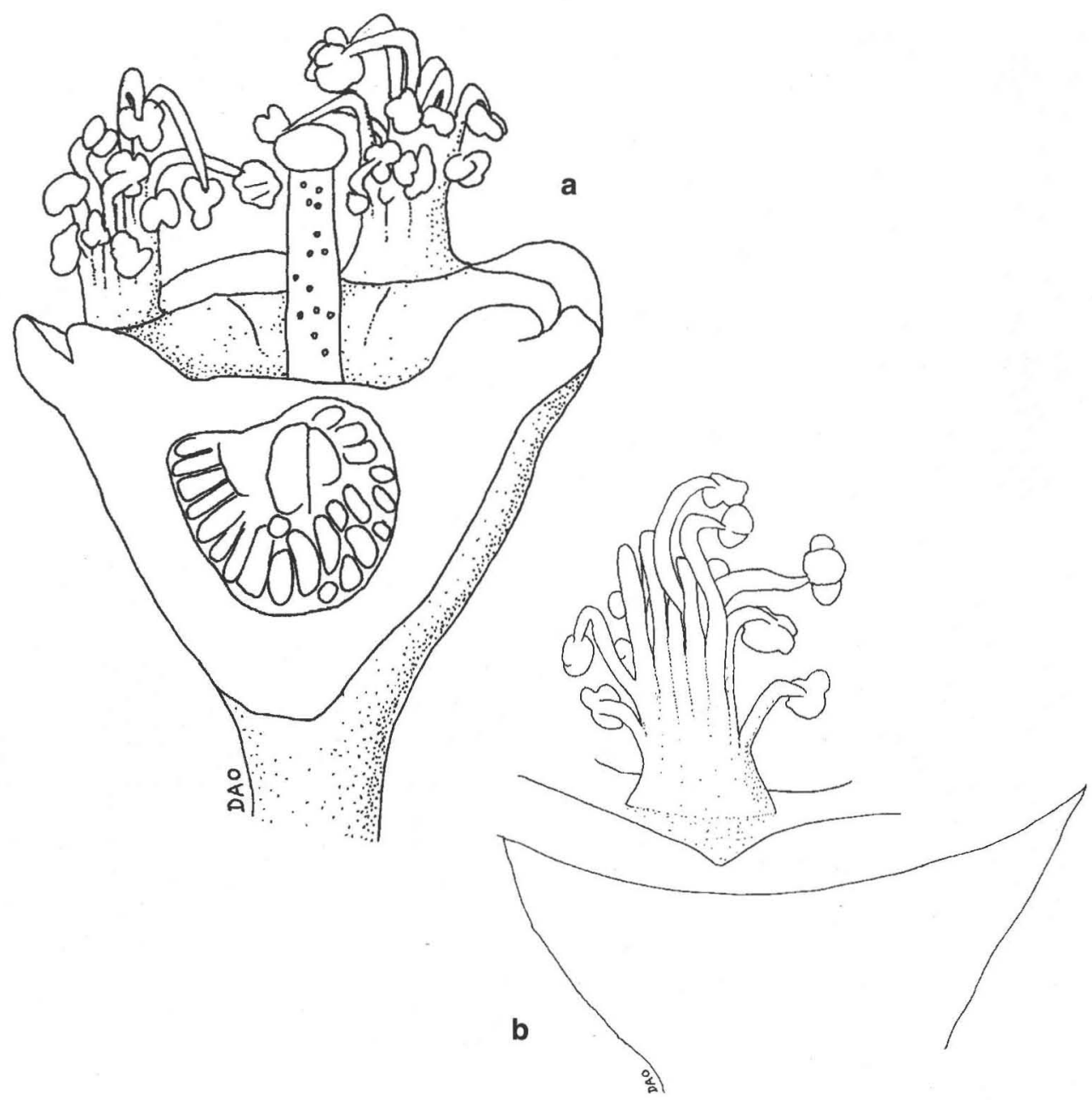

Fig. 6. Lophostemon lactifluus. a, mature half flower $(\times 18.1)$; b, stamen fascicle drawn from the back. This fascicle is not bifid ( $\times 21$ ). (from UNSW 4016). 


\section{Welchiodendron longivalve (F. Muell.) Peter G. Wilson \& J.T. Waterhouse}

Stamen bundles in mature flowers of $W$. longivalve are antepetalous and bifid (Fig. 8a,b). The first two sepals are initiated asynchronously on the floral apex in a decussate position relative to the axis and floral bract (Fig. 9a, b). The last few sepals and the petals are initiated in a spiral sequence, thus petals appear alternate to the sepal primordia on the inside of the floral tube (Fig. 9c). The spiral initiation of petal

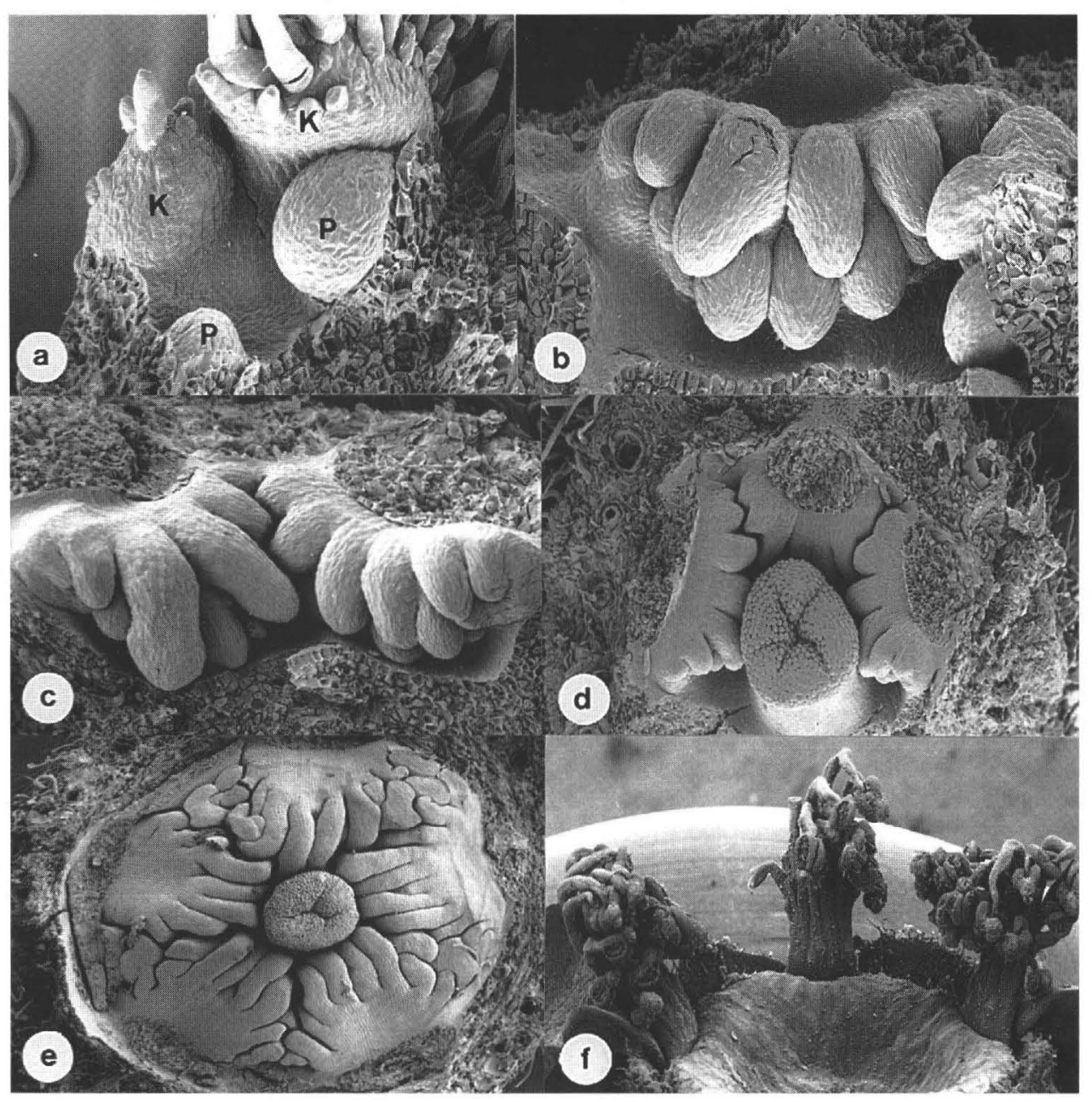

Fig. 7. Floral development of Lophostemon lactifluus. a, part of a young flower bud showing two sepal $(\mathrm{K})$ and two petal $(\mathrm{P})$ primordia. The perianth parts are initiated asynchronously $(\times 300)$; $\mathbf{b}$, stamen primordia forming on a bulge on the inner face of the invaginated floral tube. The stamen primordia are formed in a more or less symmetrical arrangement around the midline of the bundle but there is no clear groove or notch in the centre as there is in other Lophostemon spp. $(\times 300)$; c, part of a flower bud with sepals and petals removed showing two groups of stamen primordia. There is more than one row of stamen primordia in each group. The primordia in the centre of the upper row of each group are the longest indicating that they were the first ones initiated ( $\times 190)$; $d$, part of a flower bud with petals and sepals removed. Stamen primordia are fused at the bases $(\times 110)$; e, flower bud with petals and sepals removed. Both fused and free parts of the filaments have elongated $(\times 45) ; f$, mature flower showing three of the five antepetalous stamen fascicles ( $\times 17$ ). (from UNSW 4016). 
primordia is clearly evidenced by the different sizes of adjacent primordia early in development; (Fig. 9c, d). A pre-staminal bulge (PSB) develops in front of each petal primordium. Stamen primordia are initiated on the upper edge of each PSB, which develops a distinct notch in its upper edge (Fig. 9e). Stamen primordia develop first in the central region of the PSB and then at the edges (Fig. 9f). Stamen bundles develop with more or less bilateral symmetry, and there is a clear cleavage between each side of each bundle (Fig. 9g). The mature bud contains five bifid antepetalous stamen bundles (Fig. 9h).

\section{Tristaniopsis laurina (Sm.) Peter G. Wilson E J.T. Waterhouse}

Mature flowers of T. laurina have five antepetalous stamen bundles (Fig. 10). Stamens are initiated relatively early compared with Lophostemon. Stamens form on prestaminal bulges (PSBs) (Fig. 11a), which form on the flank of the concave floral apex. The first stamen primordia are initiated on the upper edge of each PSB (Fig. 11b) and subsequently further down as the flower enlarges (Fig. 11c). Expansion of the hypanthial rim occurs in the antesepalous regions and stamens are not inserted between the initial groups (Fig. 11d). Thus the stamens remain in antepetalous bundles in the mature flower (Fig. 11e). The abaxial side of the PSB does not elongate to the

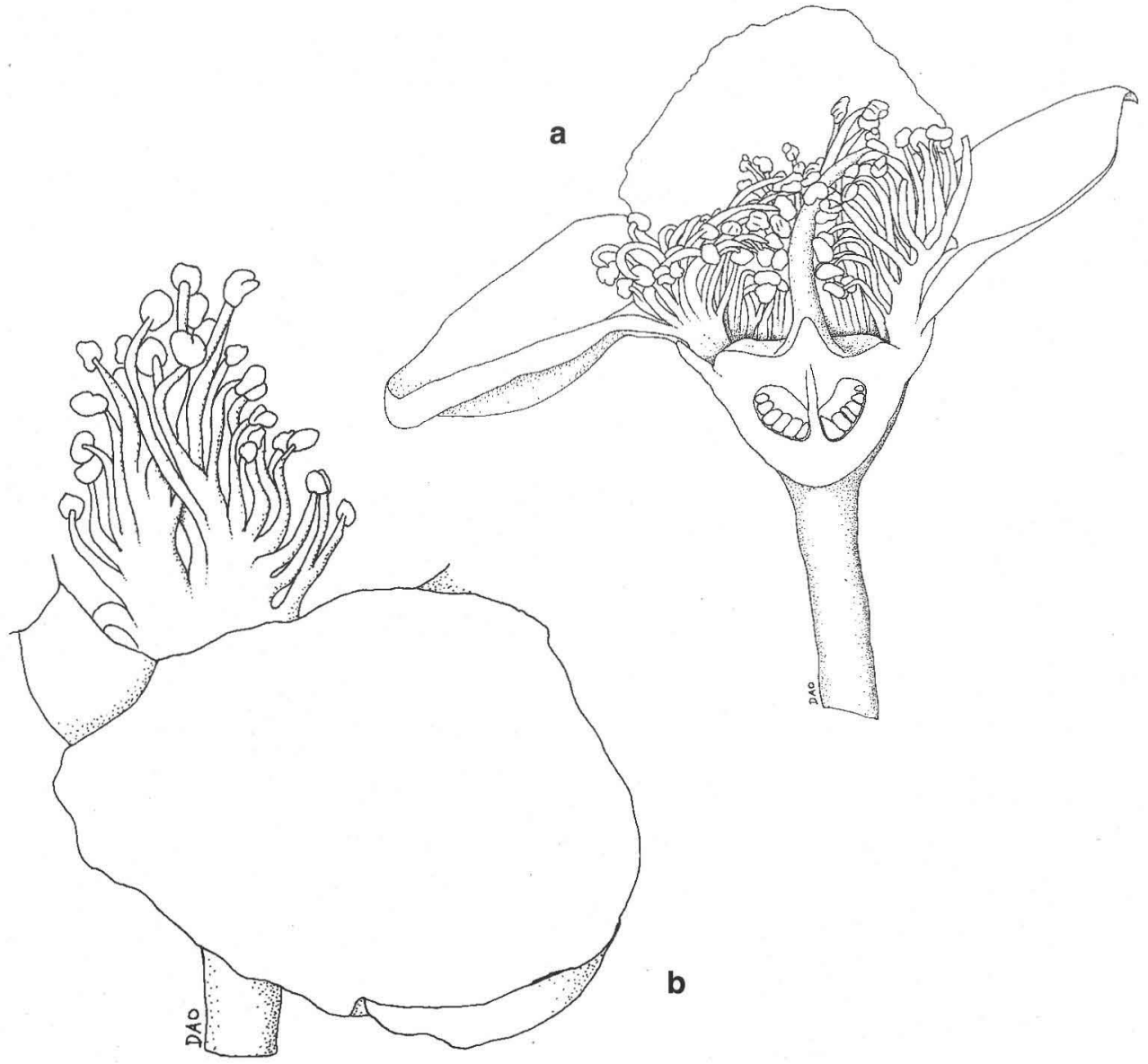

Fig. 8. Welchiodendron longivalve. a, mature half flower $(\times 4)$; $\mathbf{b}$, stamen fascicle drawn from the back (× 6.4). (a from DAO 239; b from Hyland 11042). 


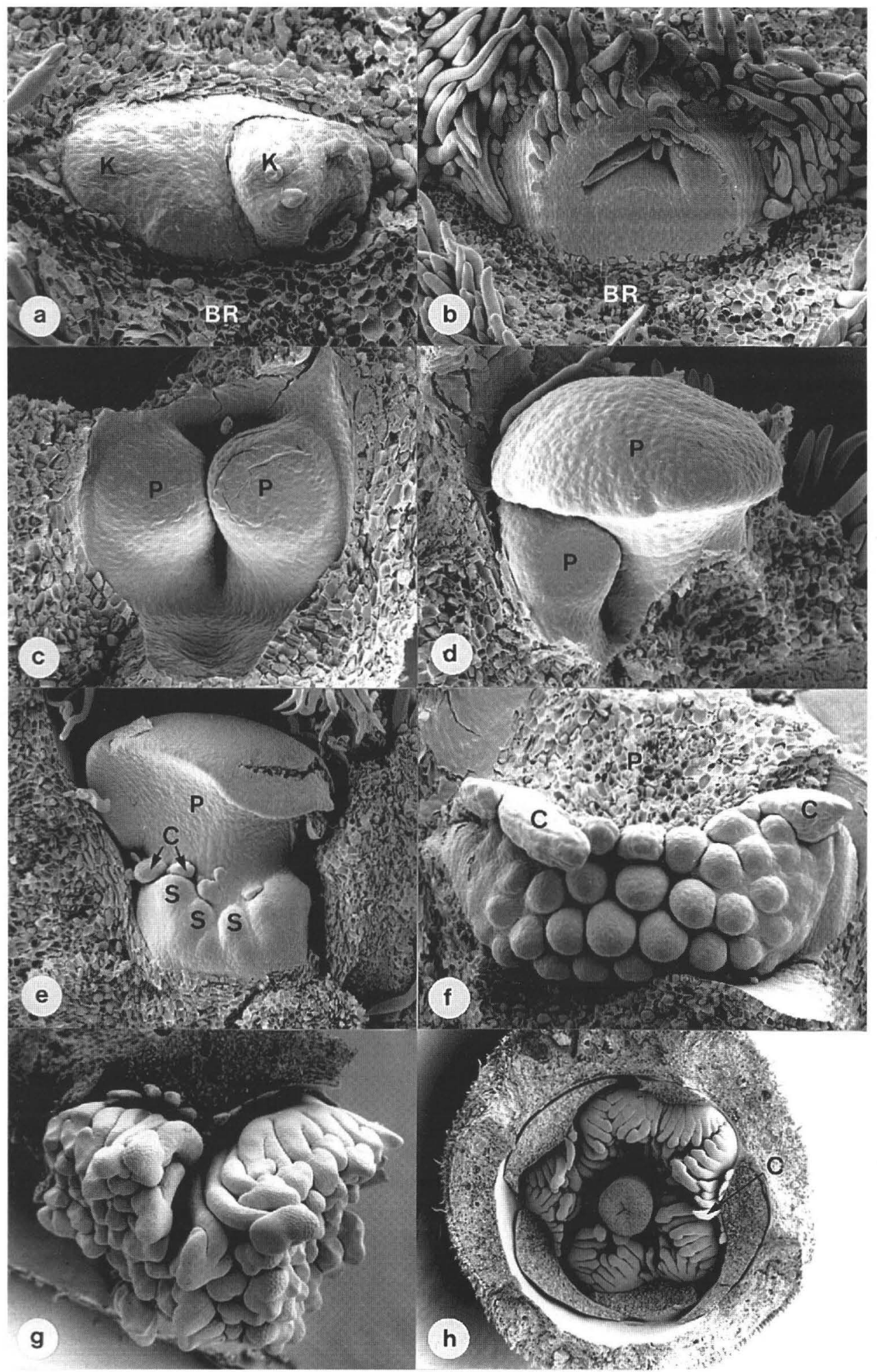


Fig. 9. (left) Floral development in Welchiodendron longivalve. a, young flower bud showing the first sepal primordia $(\mathrm{K})$. (BR - floral bract) $(\times 285)$; b flower bud after the initiation of two sepals which are initiated in a decussate position relative to the bract and main branch. (BR - floral bract) $(\times 180)$; c, the first two petal primordia (P) initiated on the inner wall of the invaginated floral apex; note the similarity in size suggests a short intervening plastochron. The first evidence of the gynoecial depression is apparent $(\times 240)$; $\mathbf{d}$, floral stage slightly later than $\mathrm{c}$. The first petal primordium $(\mathrm{P}$, right) is already quite large by the time the fourth petal primordium $(\mathrm{P}$, left) is initiated. At this stage, there is no PSB opposite either petal $(\times 220)$; e, part of a flower bud showing one petal primordium (P) and stamen primordia (S). The stamen primordia are developing on the notched upper edge of a PSB. Note the formation of colleters $(C)$ at the base of the petals but outside the zone of stamen initiation $(\times 140)$; $\mathbf{f}$, one group of stamen primordia developing opposite a petal (which has been removed). The first stamens formed along the top and in the centre of each group ( $\times 170)$; g, part of a mature flower bud showing one stamen bundle. There is a median separation of the filaments into two groups $(\times 50)$; $\mathbf{h}$, flower bud just prior to anthesis with the sepals and petals removed. Each stamen fascicle is clearly cleft. $\mathrm{C}-$ colleter $(\times 28)$. (from DAO 239).

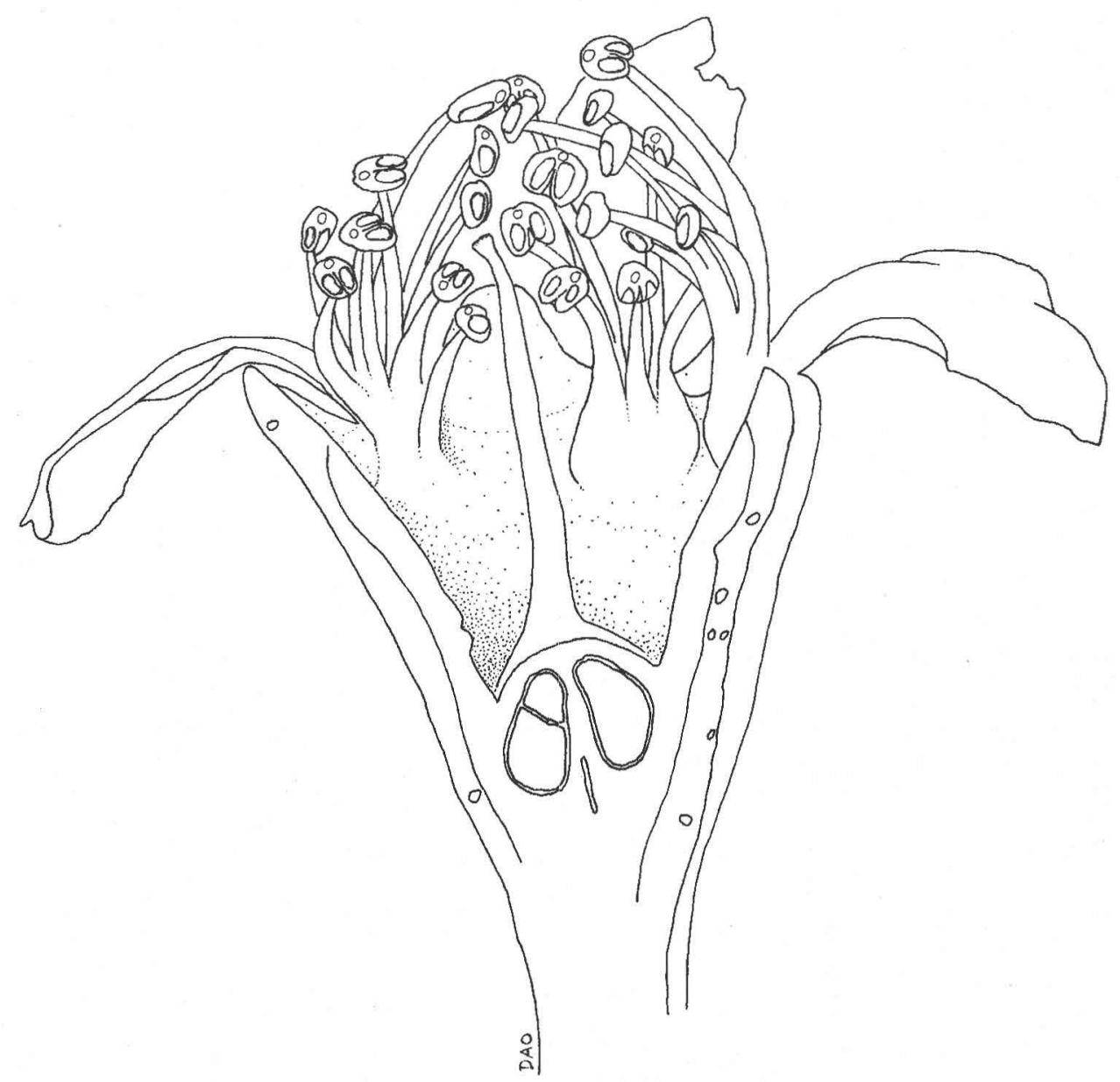

Fig. 10. Mature half flower of Tristaniopsis laurina (× 13.2). (from AND 562). 
same degree as in Lophostemon, rather the stamen filaments are fused for only a short distance. This results in the filaments being clustered in groups on the hypanthium rather than arising from the inner face of a large fascicle.

\section{Xanthostemon oppositifolius F.M. Bailey}

Mature flowers of $X$. oppositifolius have numerous stamens in a ring around the hypanthium (Fig. 12). The stamens are not fused and there are generally two rows in front of the petals and a single row in front of the sepals. The petal primordia form alternately to the sepal primordia on the inside of the floral tube. There is no prestaminal bulge prior to stamen initiation. As the petal primordia enlarge (Fig. 13a-d), two stamen primordia are initiated on the floral tube in front of each petal. Subsequent

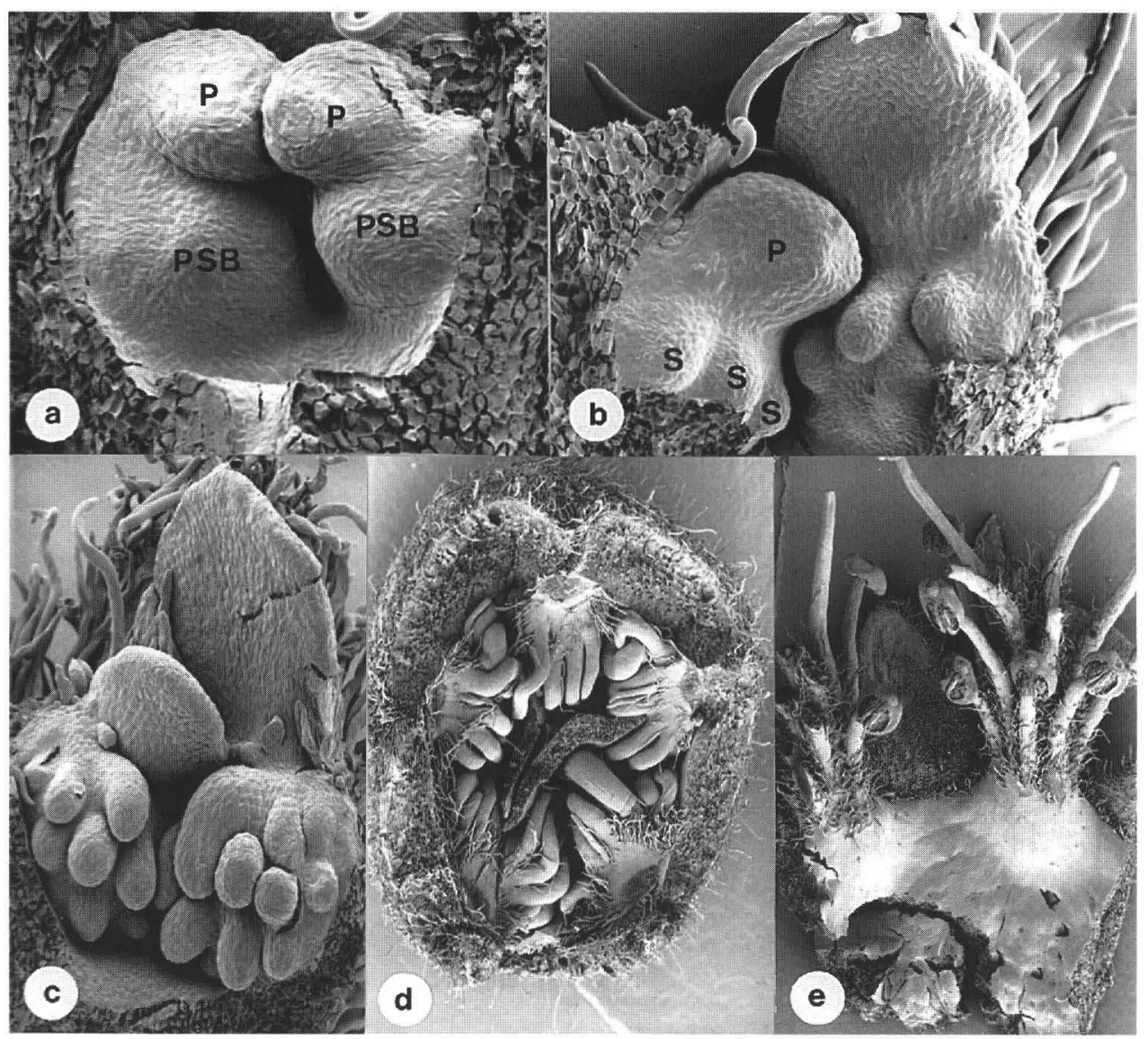

Fig. 11. Floral development of Tristaniopsis laurina. a, part of a young flower bud showing two adjacent petal primordia (P). There is a pre-staminal bulge (PSB) in front of each petal primordium $(\times 305)$; b, two adjacent petal primordia. The difference in size of the petal primordia reflects their asynchronous initiation. Stamen primordia (S) arise from the PSB in front of the petals $(\times 215)$; c, petal and stamen primordia at a later stage of development. The difference in size between adjacent primordia is still apparent. More stamen primordia are inserted beneath and around the original ones $(\times 170)$; $d$, flower bud with sepals and petals removed. Bundles of antepetalous stamens are distributed around the hypanthium $(\times 20.5)$; e, part of a mature flower showing two groups of stamens. Filaments are not fused but remain grouped in front of the petals. The hypanthium is slightly raised where the filaments are attached ( $\times 16)$. (from AND 561). 
stamens are formed around and directly in front of those first formed (Fig. 13e-h), resulting in vertical rows of stamen primordia. The outer rows of stamens appear more or less evenly spaced in immature buds (Fig. 13i). Swelling of the petal bases gives the appearance of stamen clustering around the petals in the outer stamen row of more mature buds (Fig. 13j). Expansion of the hypanthium as the flower enlarges results in the spreading-out of the stamens to form a ring in the mature flower. Because there is relatively less hypanthial expansion in the antepetalous regions, stamens are less severely displaced from their position of insertion, thus they appear several rows deep.

\section{Xanthostemon verticillatus (C. White \& Francis) L.S. Smith}

Petals are initiated on the inside of the floral tube (Fig. 14a). Stamen primordia are initiated directly on the flank of the invaginated floral tube in front of the petals (Fig. 14b). The hypanthium expands and the outer row of stamen primordia form a ring around the hypanthium (Fig. 14c). Subsequent stamens are formed in vertical rows in front of the first-formed ones (Fig. 14d-g). The outer row of stamens appear to be clustered around the petals due to increase in size of the petal bases (Fig. 14h) and small clusters of colleters in the antesepalous positions (Fig. 14i). The stamens form an outer discontinuous ring (Fig. 14i) in which there are no stamens in the positions immediately opposite the sepals.

\section{Lysicarpus angustifolius (J.D. Hook.) Druce}

Mature flowers have a ring of stamens around the rim of the hypanthium, and clusters of stamens opposite the petals (Fig. 15). The first stamen primordia are initiated on the inner wall of the floral tube as it develops subsequent to petal initiation (Fig. 16a). There is no pre-staminal bulge; stamens are initiated directly on the hypanthium in an irregular order as new space becomes available. Up to 60

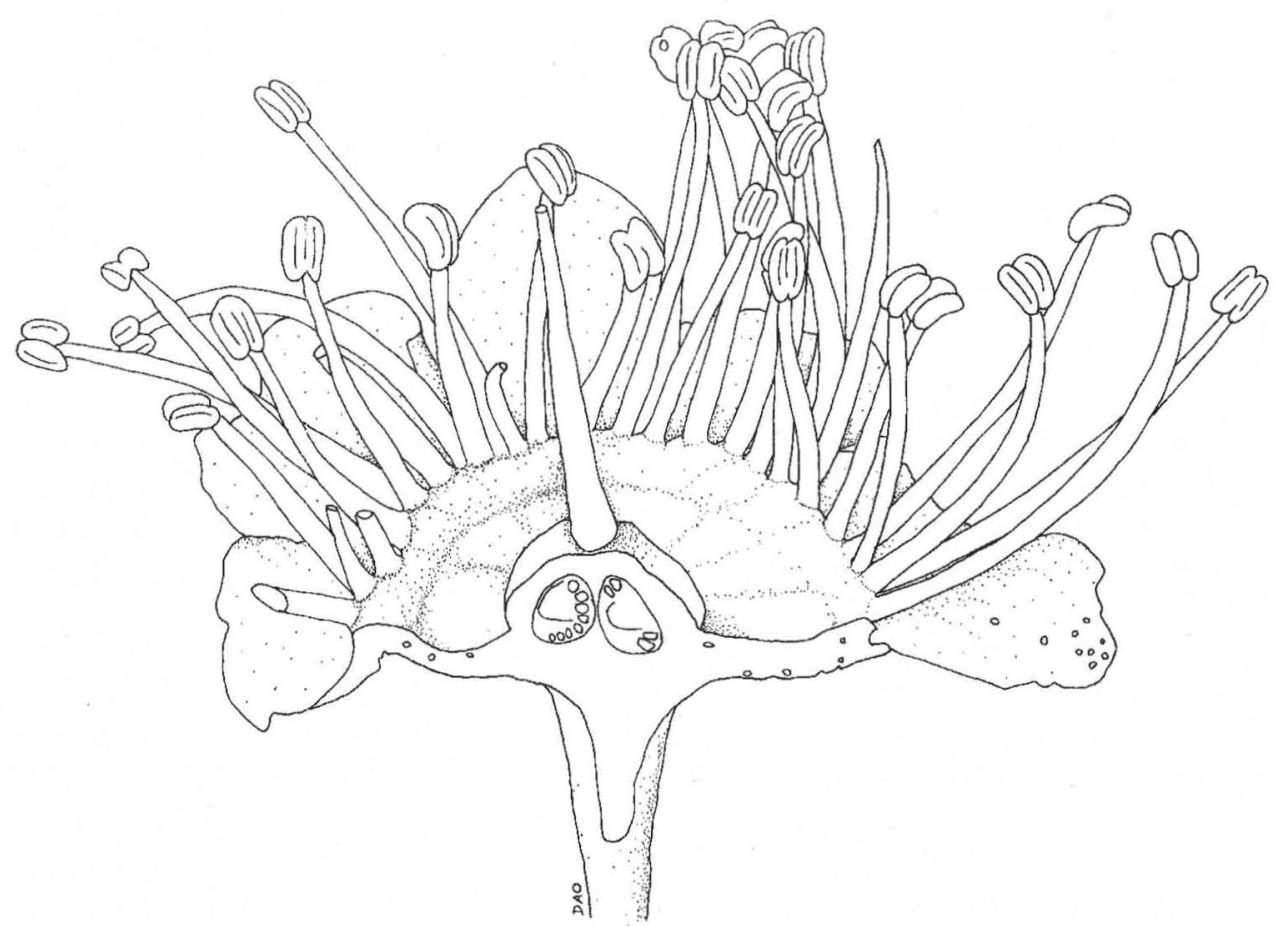

Fig. 12. Xanthostemon oppositifolius. Mature half flower (× 8.1). (from DAO 221). 


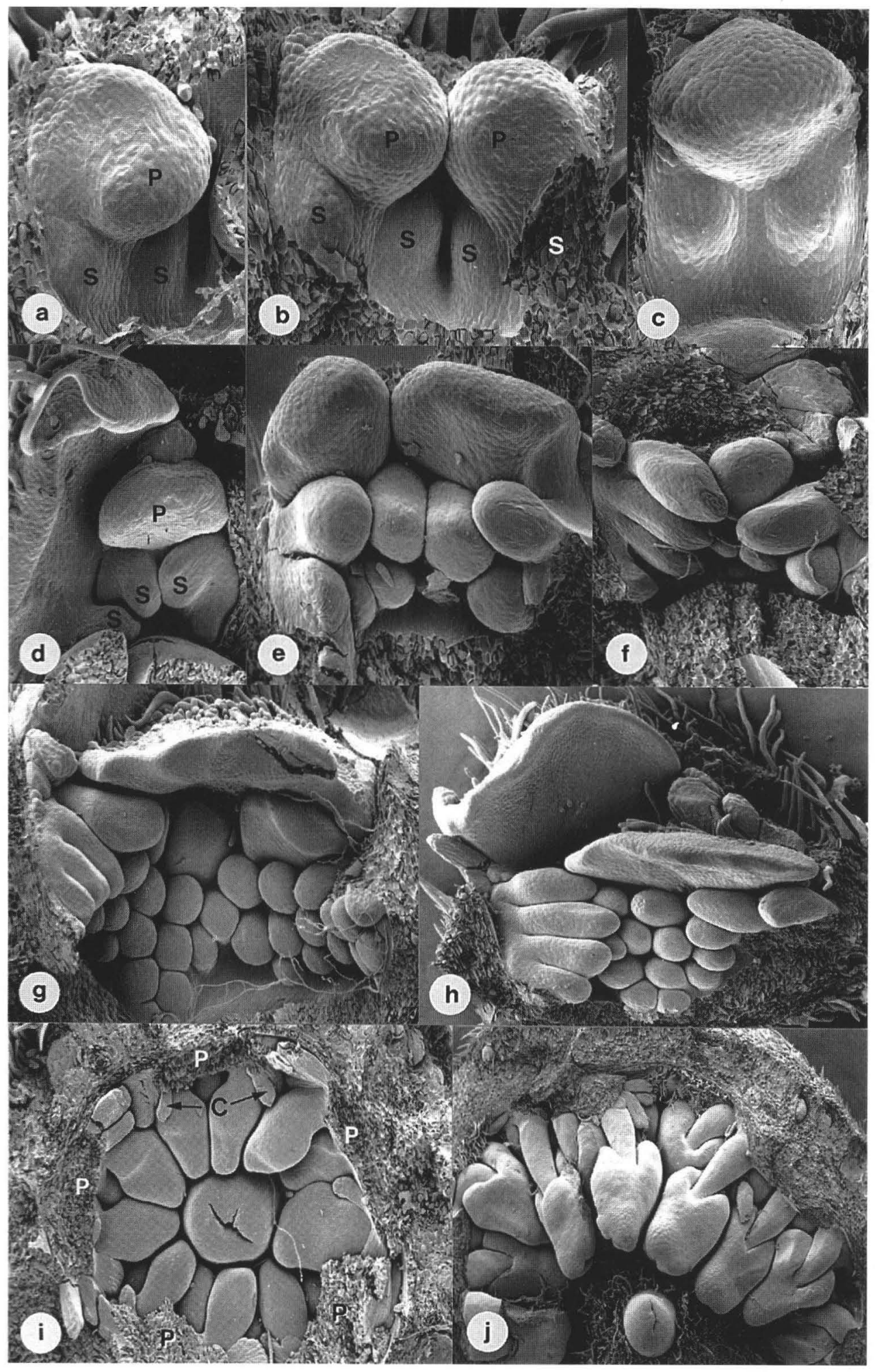


stamens are initiated in several tiers (Fig. 16b). Expansion of the hypanthium as the flower enlarges causes many of the stamens to be spread out on the mature flower (Fig. 16c), but failure of the hypanthium to expand in the region directly in front of the petals leaves some stamens clustered in those areas (Fig. 16d). There is no fusion of filaments within the antesepalous stamen clusters.

\section{Metrosideros collina (J.R. \& G. Forst.) A. Gray var. villosa (L. f.) A. Gray}

Mature flowers of $M$. collina var. villosa have a single row of free stamens around the edge of the hypanthium (Fig. 17). Small swellings that may represent pre-staminal bulges develop on the hypanthium following initiation of the petal primordia (Fig. 18a). Stamens are initiated in a single row on each swelling (Fig. 18b). As the bud matures (Fig. 18c, d, e), the filament bases enlarge to fill the circumference of the hypanthium. No new stamens are initiated and the small pre-staminal bulges do not enlarge. At anthesis, the stamens form a complete ring (Fig. 18f). Occasionally there is a gap in an antesepalous region but gaps were not observed in antepetalous regions. Occasionally two filaments are fused together (Fig. 18f).

Tristania neriifolia (Sims) R. Br.

Mature flowers of Tristania neriifolia have five sepals, five petals and five antepetalous groups of stamens arranged in a ring around the hypanthium (Fig. 19). Filaments in each stamen group are fused for about half of their length and each group of stamens is shortly united at the base. During bud development, a stamen is first initiated opposite each petal primordium on the flank of the invaginated floral apex. Two further stamens are initiated on either side of the first resulting in a group of three stamens opposite each petal (Fig. 20a). Occasionally, one or two extra stamens are inserted between the regular antepetalous groups (Fig. 20a). A small degree of hypanthial expansion in the antesepalous region accounts for the separation of stamens into antepetalous groups (Fig. 20b).

\section{Thaleropia queenslandica (L.S. Smith) Peter G. Wilson}

The leaves of T. queenslandica are opposite and this pattern is continued in the sepal primordia. Two pairs of opposite sepal primordia are present in young buds followed by a fifth sepal primordium inserted adjacent to one of the second pair of sepal primordia. Five, or occasionally up to seven, petal primordia form more or less alternate to the sepals. They are initiated asynchronously, resulting in petal primordia of differing developmental sizes during flower ontogeny. Stamen primordia are inserted around the inside of the hypanthium, initially with one stamen more or less in front of each petal primordium and several more stamens are initiated in between those first formed (Fig. 21a-c). There is variability in perianth and stamen numbers in individual flowers. Only the oldest stamens are antepetalous, the younger one or several being lower in the concave floral tube and not clearly antepetalous (Fig. 21d).

Fig. 13. (left) Floral development of Xanthostemon oppositifolius. a, petal primordium (P). There are two swellings beneath the petal primordium which are stamen primordia $(S)(\times 240)$; $\mathbf{b}$, two petal primordia (P). There are three stamen primordia visible and one cut away $(\mathrm{S})$ and there is a depression between each antepetalous group of stamens $(\times 300)$; c, petal primordium and two stamen primordia $(\times 250)$; d, part of a flower bud showing three stamen (S) primordia in a single row. $\mathrm{P}-$ petal $(\times 150)$; e, two petal primordia and two rows of stamen primordia $(\times 200)$; f, stamen primordia. A petal primordium has been removed. Stamens are initiated in vertical rows beneath the original antepetalous stamens ( $\times 190) ; \mathbf{g}, \mathbf{h}$, half flower bud showing the vertical rows of stamen primordia ( $\mathrm{g} \times 120 ; \mathbf{h} \times 100$ ); i, flower bud with petals $(\mathrm{P})$ removed. Pairs of stamen primordia are situated on either side of each petal scar. Note colleters $(C)$ at the base of the petals $(\times 90) ; \mathbf{j}$, mature flower bud with petals removed. The petal bases are swollen and the distance between petals is increased ( $\times 30)$. (from DAO 221). 


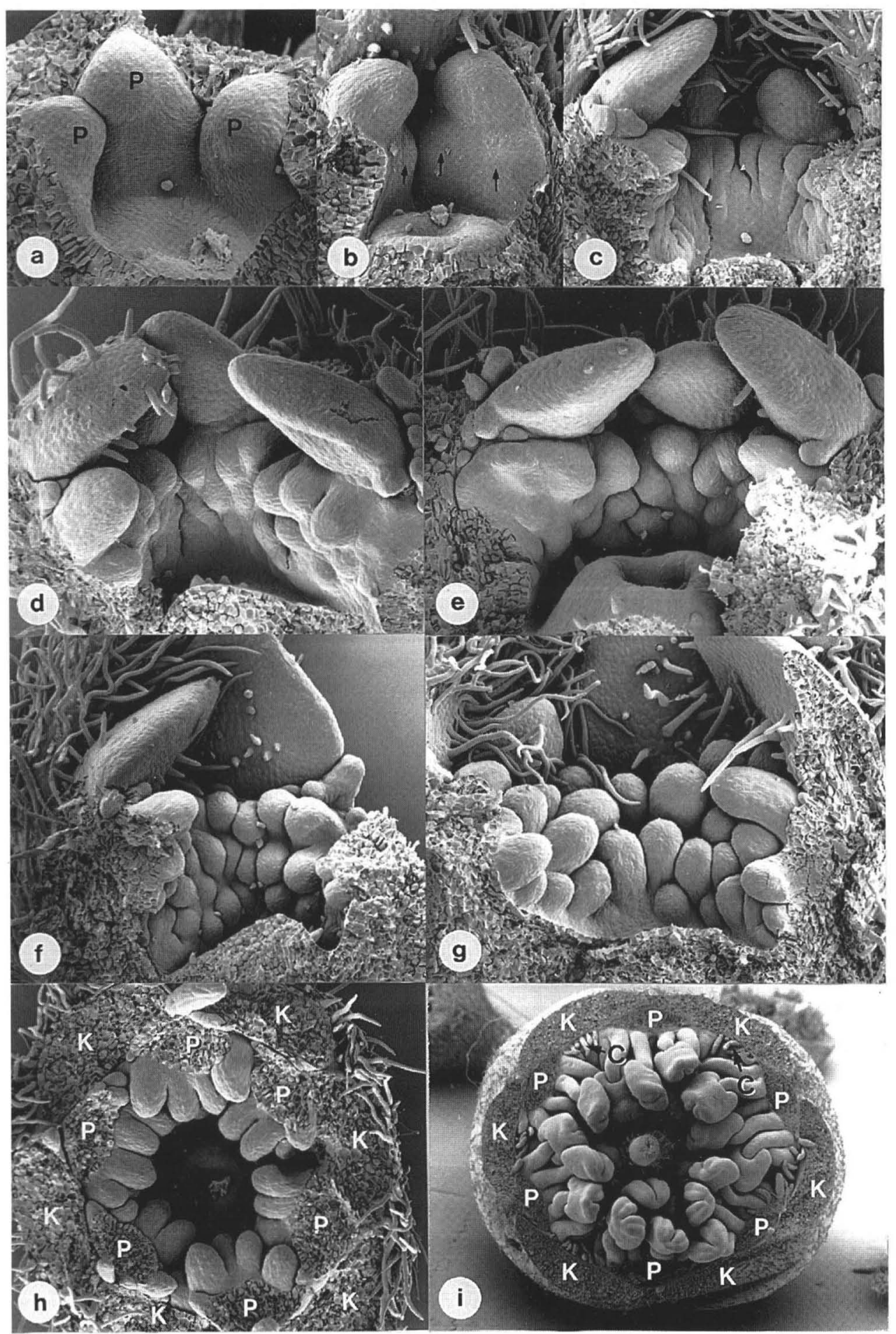


Fig. 14. (left) Floral development of Xanthostemon verticillatus. a, young half flower bud with three petal primordia $(\mathrm{P})$. Sepals have been removed. The floral apex is beginning to invaginate. No stamen primordia are visible at this stage $(\times 160)$; $\mathbf{b}$, two petal primordia. Stamen primordia are just visible as small swellings in front of each petal primordium (arrows) $(\times 130)$; c, half flower bud. Stamens are initiated in a ring around the rim of the developing hypanthium $(\times 95)$; d, flower bud with several rows of stamen primordia ( $\times 130)$; e, half flower bud. Stamen primordia in the second or lower rows are not preferentially initiated opposite petals however they are arranged in more or less vertical columns $(\times 125)$; $\mathbf{f}$, part of a flower bud showing two petals and developing stamens. The stamens are initiated in vertical columns and are tightly packed ( $\times 100)$; g, part of a flower bud showing the initiation of new stamen primordia in available spaces between older ones $(\times 110)$; $\mathbf{h}$, flower bud with sepals $(K)$ and petals $(P)$ removed. Stamens in the first row appear to be clustered around the petals due to swelling of the petal base ( $\times 95)$; $\mathbf{i}$, mature flower bud with sepals $(\mathrm{K})$ and petals $(\mathrm{P})$ removed. Stamens are beginning to elongate. The region of hypanthium opposite each sepal has small hairs. The hypanthium is expanding in the antesepalous regions and there are clusters of colleters $(C)$ in this position $(\times 15)$. (from $D A O 36)$.

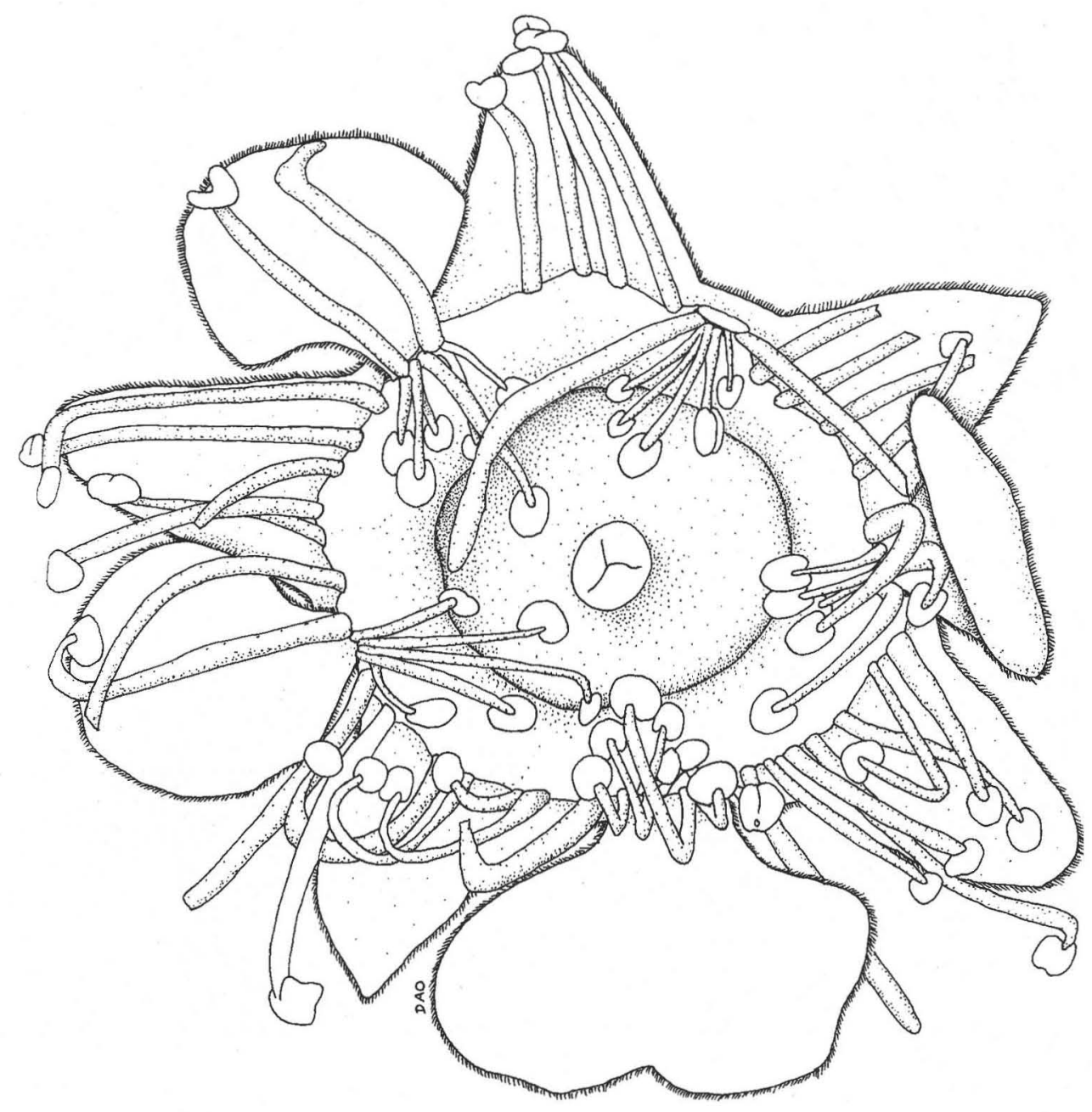

Fig. 15. Lysicarpus angustifolius. Mature half flower (× 14). (from PGW 569). 


\section{Discussion}

The basic pattern of flower development is essentially the same for all taxa studied here, and is similar to that described for other genera of Myrtaceae (Payer 1857, Leins 1965, Mayr 1969, Bunniger 1972, Drinnan \& Ladiges 1988, 1989a,b,c, 1991a,b, Ronse Decraene \& Smets 1991). The flower apical meristem is convex only until the first couple of sepal primordia are initiated, after which it becomes prominently invaginated, and the subsequent perianth primordia form on the steeply inclined wall of the developing floral tube. The first two sepals are positioned in a more or less opposite pair in the median plane (decussate to the floral prophylls), but spiral phyllotaxy is quickly attained and continued into the corolla. The order of initiation of the floral organs does not follow a strict centripetal order in any of the flowers examined; sepals and petals are formed in order, but the first signs of the gynoecium are apparent before the inception of stamen primordia. Stamen primordia are inserted in the

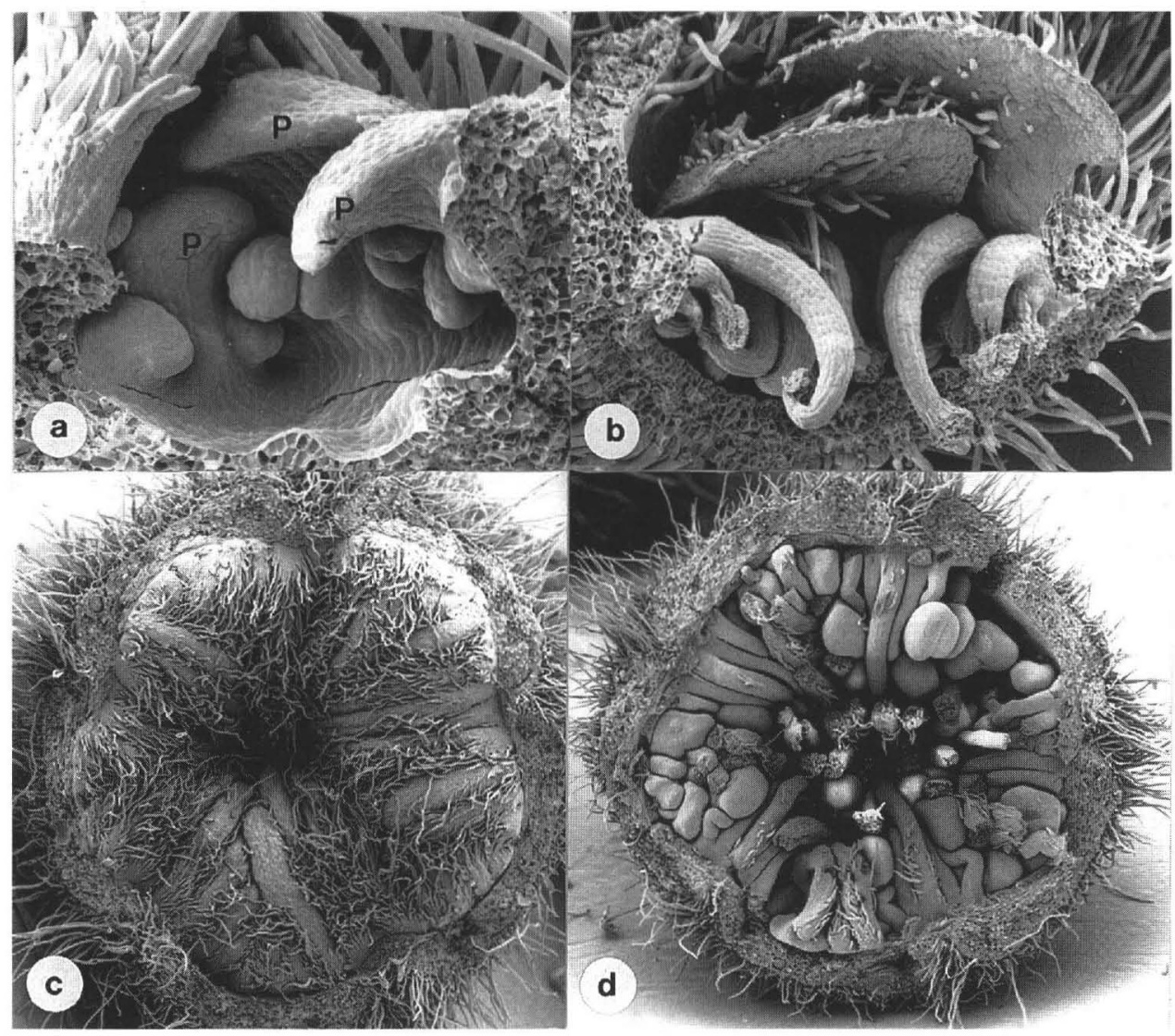

Fig. 16. Floral development in Lysicarpus angustifolius. a, young half flower bud showing petal (P) and stamen primordia. The first stamens are initiated between the petals. Later primordia are initiated lower down on the hypanthium and are antepetalous $(\times 200)$; b, part of a more mature flower bud showing the long stamen filaments of the outer whorl $(\times 90)$; $c$, mature flower bud with sepals and petals removed showing the outer whorl of stamen filaments covered in hairs $(\times 23)$; d, flower bud of a similar age to that in (c) with the outer whorl of stamens removed. The inner stamens are grouped into antepetalous bundles $(\times 23)$. (from PGW 569). 
expanding hypanthial region between the developing corolla and gynoecium. Much has been written on the nature of the hypanthium and the problems of terminology in flowers with deeply concave floral apices, and we do not intend to enter that controversy in any substantial way. We consider the inclined walls of the sunken floral apex equivalent to the flank of the apical dome of a normal, convex, floral meristem, and the resultant hypanthium to be either basically axial or de novo, but not in any way equivalent to, or modified from, the bases of the floral organs.

The spiral phyllotaxy of the corolla is an important determinant of flower form. Because petal primordia are sequentially initiated, they are all at different stages of development at any one time. The positions of the petal primordia influence the sites available for stamen initiation, so the degree to which petal initiation and development is asynchronous determines variation similarly in the androecium.

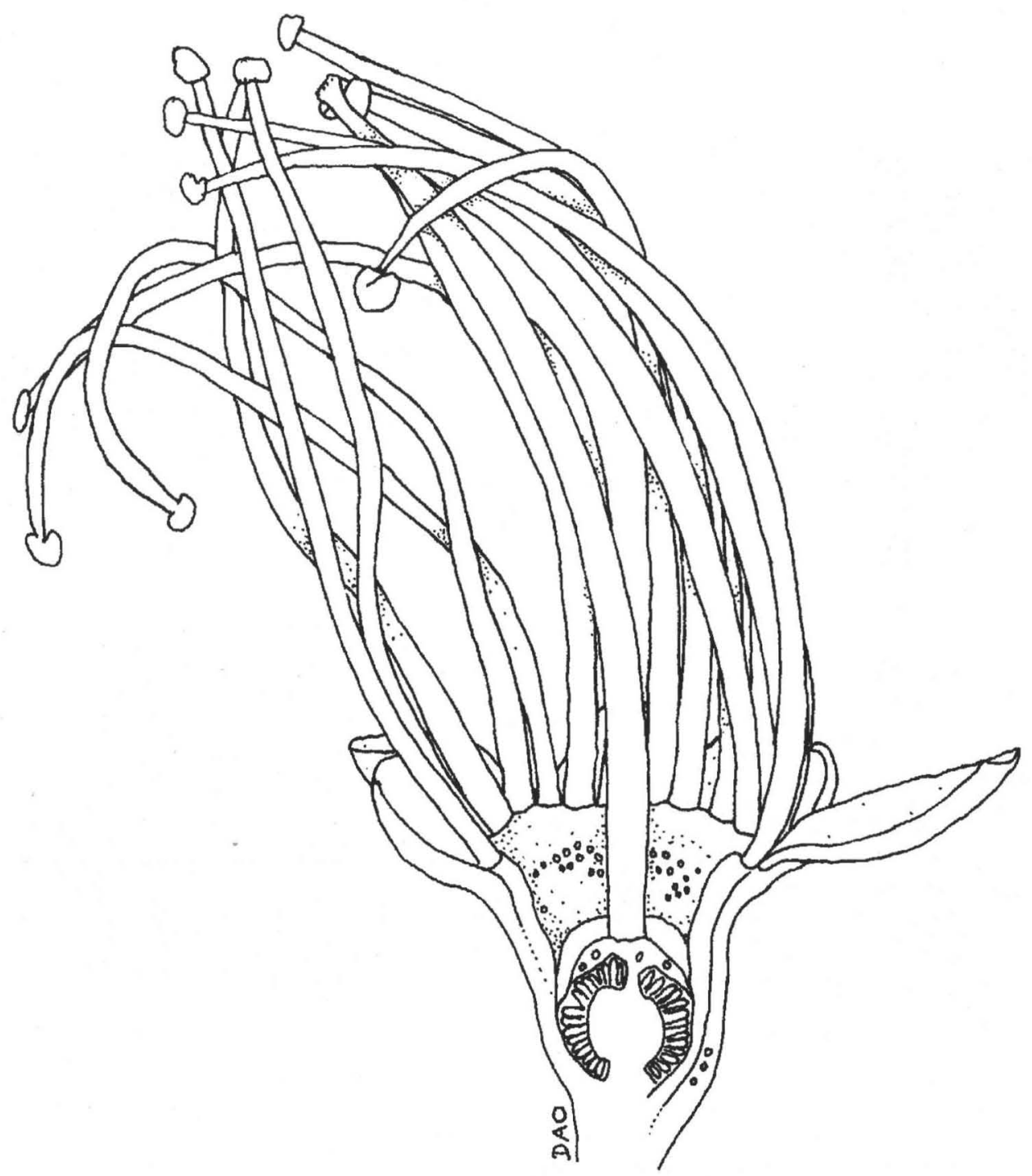

Fig. 17. Metrosideros collina var. villosa. Mature half flower (× 7.9). (from DAO 44). 


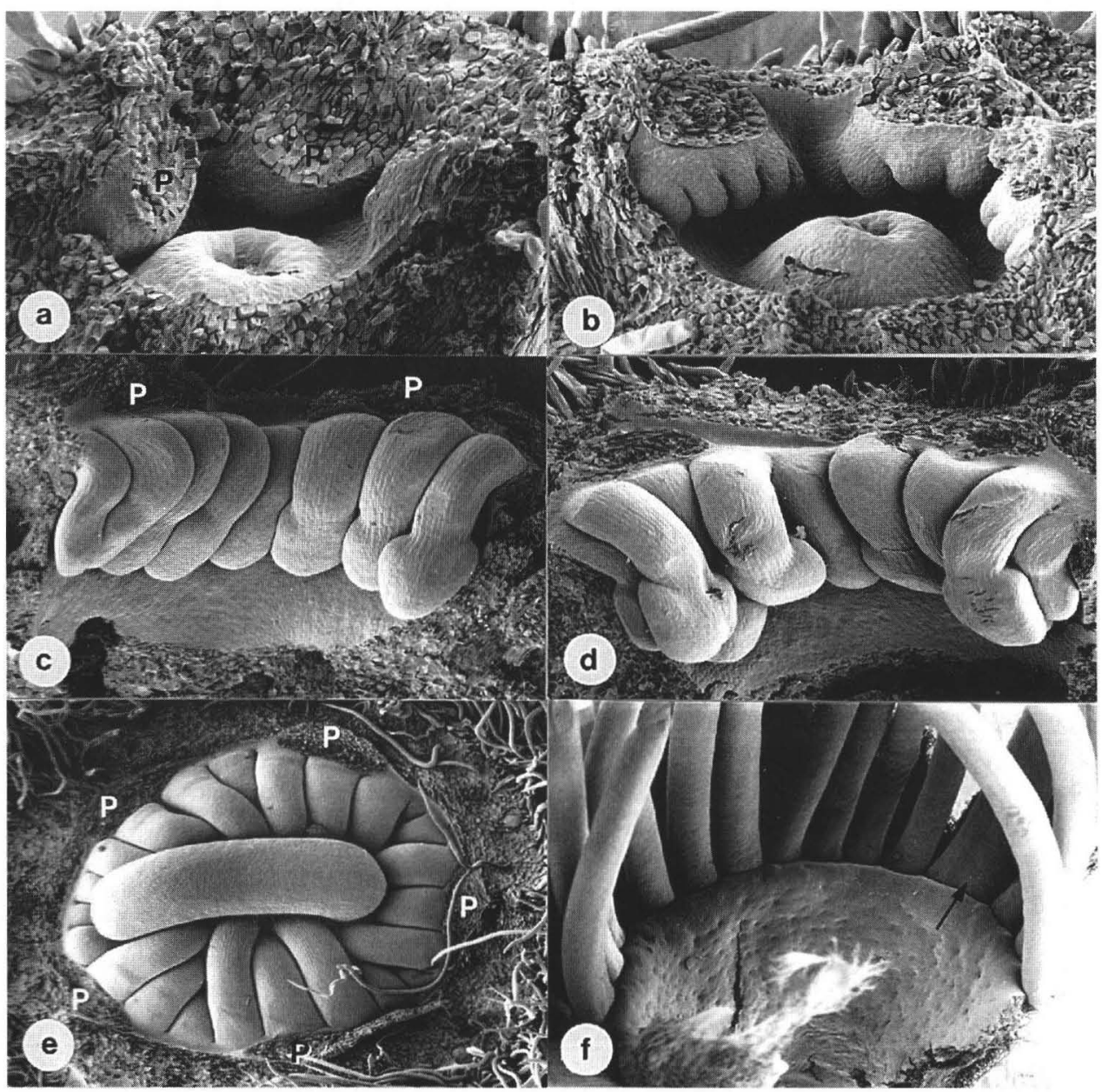

Fig. 18. Floral development of Metrosideros collina var. villosa. a, part of a young flower bud. Sepal and petal primordia have been removed and two petal scars are visible $(\mathrm{P})$. There is a small PSB in front of each petal scar and individual stamen primordia are not present $(\times 200)$; b, part of a flower bud at a stage where individual stamen primordia are visible. Sepal and petal primordia have been removed. The stamens are initiated in a single row on antepetalous PSBs and occur in groups centripetal to each petal. There is a gap between each group of stamen primordia $(\times 170)$; $c$, the space between each group of filaments closes as the filaments become larger ( $\mathrm{P}-$ petal scars) $(\times 105)$; $\mathbf{d}$, developing stamens form a continuous ring around the developing hypanthium but appear grouped in front of the petals due to small differences in position of insertion ( $\times 100)$; e, entire flower bud with sepals and petals removed. Petal scars are indicated $(\mathrm{P})$. The initial grouping of stamens in front of each petal is still discernible $(\times 50)$; $f$, part of a mature flower with a more or less continuous ring of free filaments around the rim of the hypanthium. There is a gap between two filaments in a position opposite a sepal but not between filaments opposite petals. Occasionally two filaments are fused (arrow) (× 13.5). (from $D A O 44)$. 


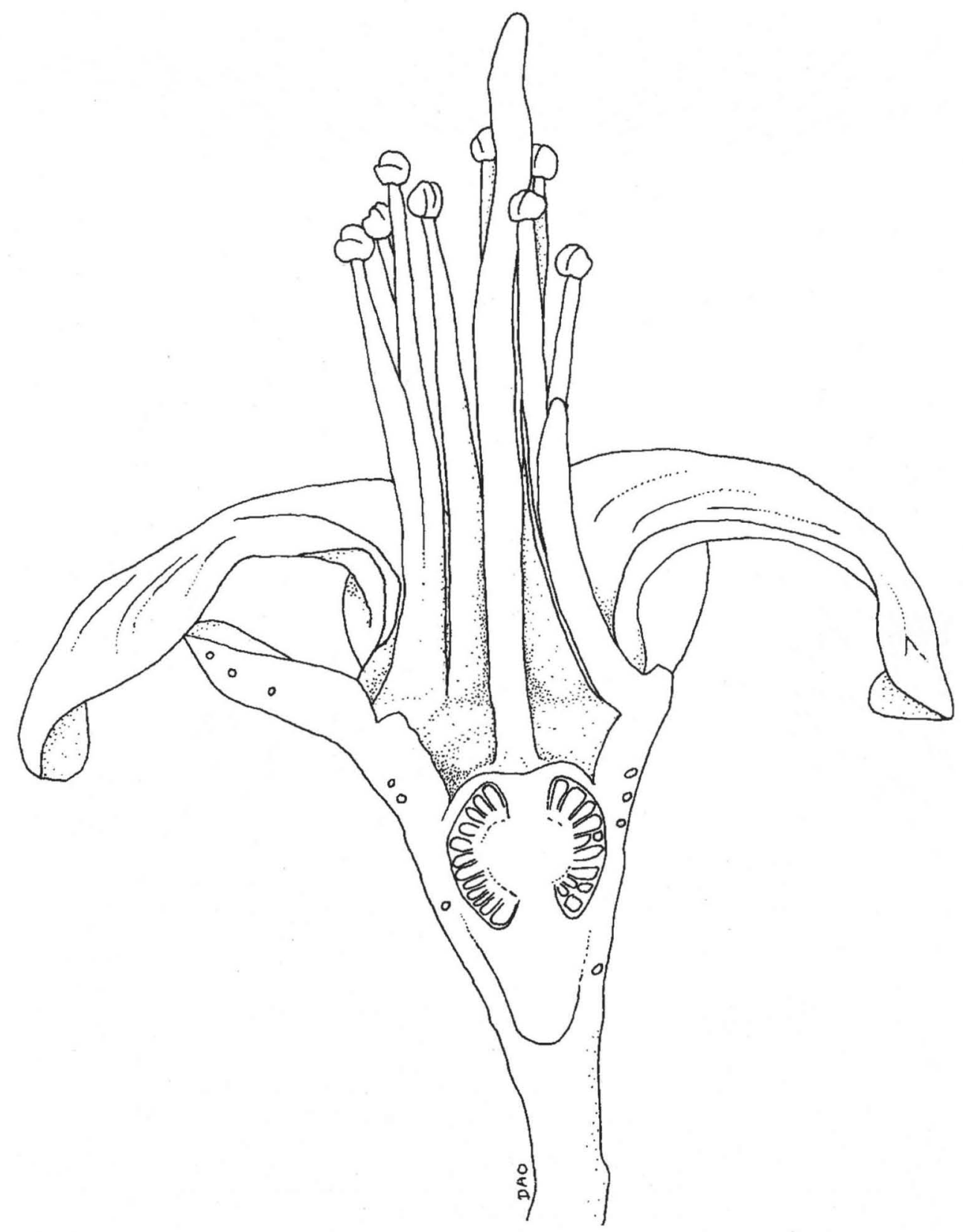

Fig. 19. Tristania neriifolia. Mature half flower (× 13.2). (from DAO 169). 
For example, the first and fourth petal are adjacent to each other in the flower, but the difference between their sizes remains evident for some time. The same is true for the second and fifth petal. Petals four and five, which are often in close proximity in their early development, are never very different in size. This is most easily seen in Lophostemon confertus (see Fig. 2), and it is evident to some extent in all taxa.

Three categories of stamen arrangement are present in mature flowers. Lophostemon, Welchiodendron and Tristaniopsis have stamens united into distinct, antepetalous fascicles; Xanthostemon and Lysicarpus have clusters of stamens in front of the petals, but also have stamens distributed around the hypanthial rim in the antesepalous regions; Metrosideros collina has evenly distributed stamens that do not express any obvious clustering. The small amount of material available for Thaleropia queenslandica and Tristania neriifolia preclude confident assignment to any of these groups. The difference between these three conditions can be accounted for by different spatial and temporal factors in the ontogeny of the flower, both during and subsequent to organ initiation.

The genera that have their stamens united into a distinct fascicle are characterised by the formation of a pre-staminal bulge on which individual stamen primordia are initiated. This is best demonstrated by Lophostemon confertus. In this species stamen initiation is a relatively late event in early floral ontogeny, by which stage the petals

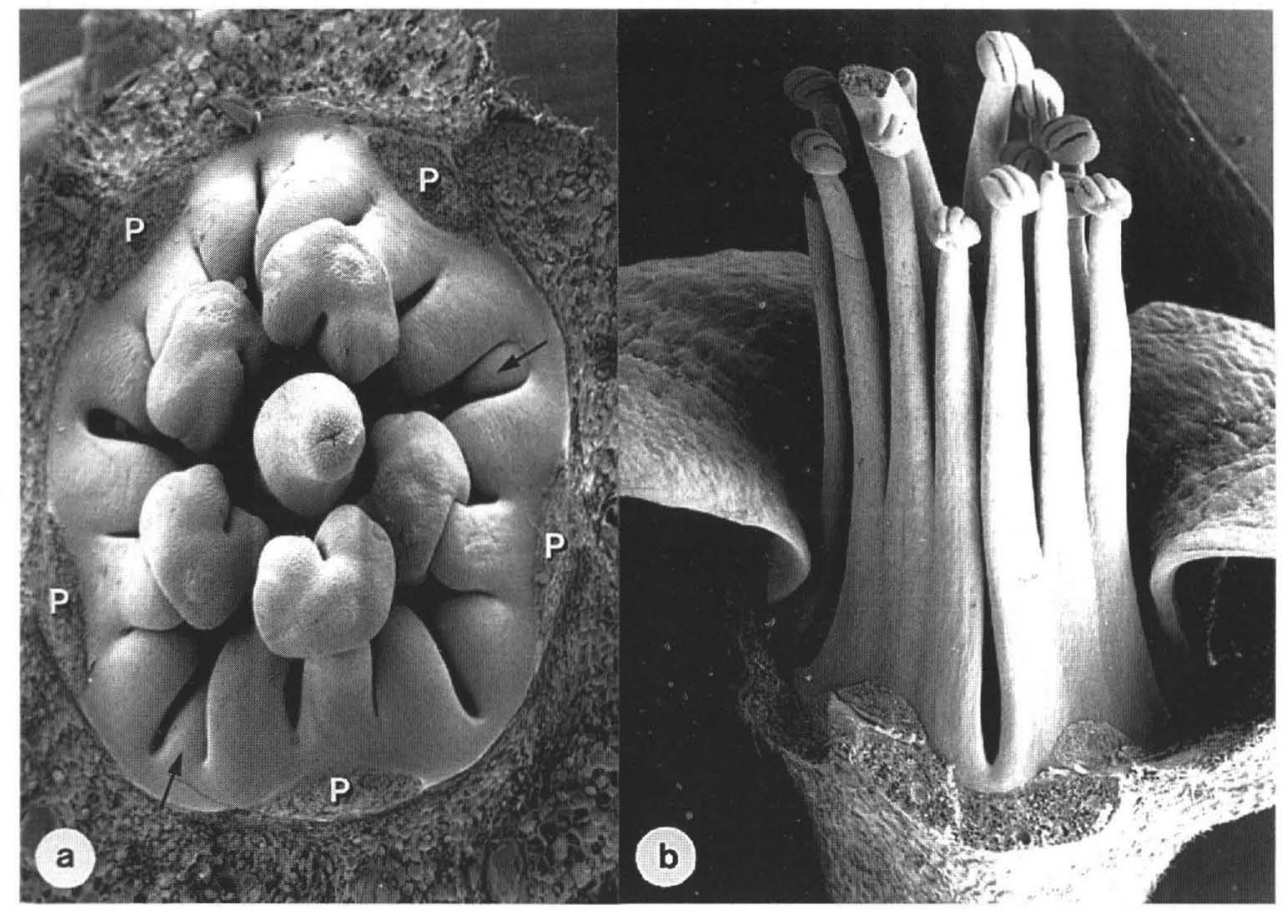

Fig. 20. Tristania neriifolia. a, flower bud with sepals and petals $(\mathrm{P})$ removed. Stamen primordia are arranged in five groups of approximately three stamens. The central stamen primordium in each group is opposite a petal and there is a gap between each group of stamens. The development of the central stamen primordium in each group is more advanced than that of the outer two. Note the occasional presence of stamen primordia (arrows) in the antesepalous position $(\times 50)$; $b$, mature flower with two sepals and petals removed. Stamens are fused into five groups of three stamens for approximately half of the length of the filaments. The central stamen in each group is longer than the other two $(\times 17)$. (from $D A O 169)$. 
have reached a considerable size and gynoecium formation is well underway. The pre-staminal bulge that has developed in front of each petal is well formed, and has two recognisable halves separated by a vertical groove. It was not possible to determine unequivocally the exact relationship between the petal primordium in the strict sense and the pre-staminal bulge, but we interpret them here as independent structures. Because of the invaginated nature of the floral apex the pre-staminal bulge gives the appearance of having formed on the base of the developing petal primordium. However, this region of the cone is actually the flank of the floral apex immediately acropetal to the petal primordia, and it is more likely that the prestaminal bulge forms on the floral apex proper. Species of Eucalyptus informal subgenus Eudesmia also have stamens that form on an antepetalous buttress. However, these buttresses were interpreted as modified corolline components that are homologous to the petals of Angophora and the bloodwood eucalypts (Corymbia) (Drinnan \& Ladiges 1988, 1989a,b). They are not equivalent to pre-staminal bulges in Lophostemon, Welchiodendron and Tristaniopsis.

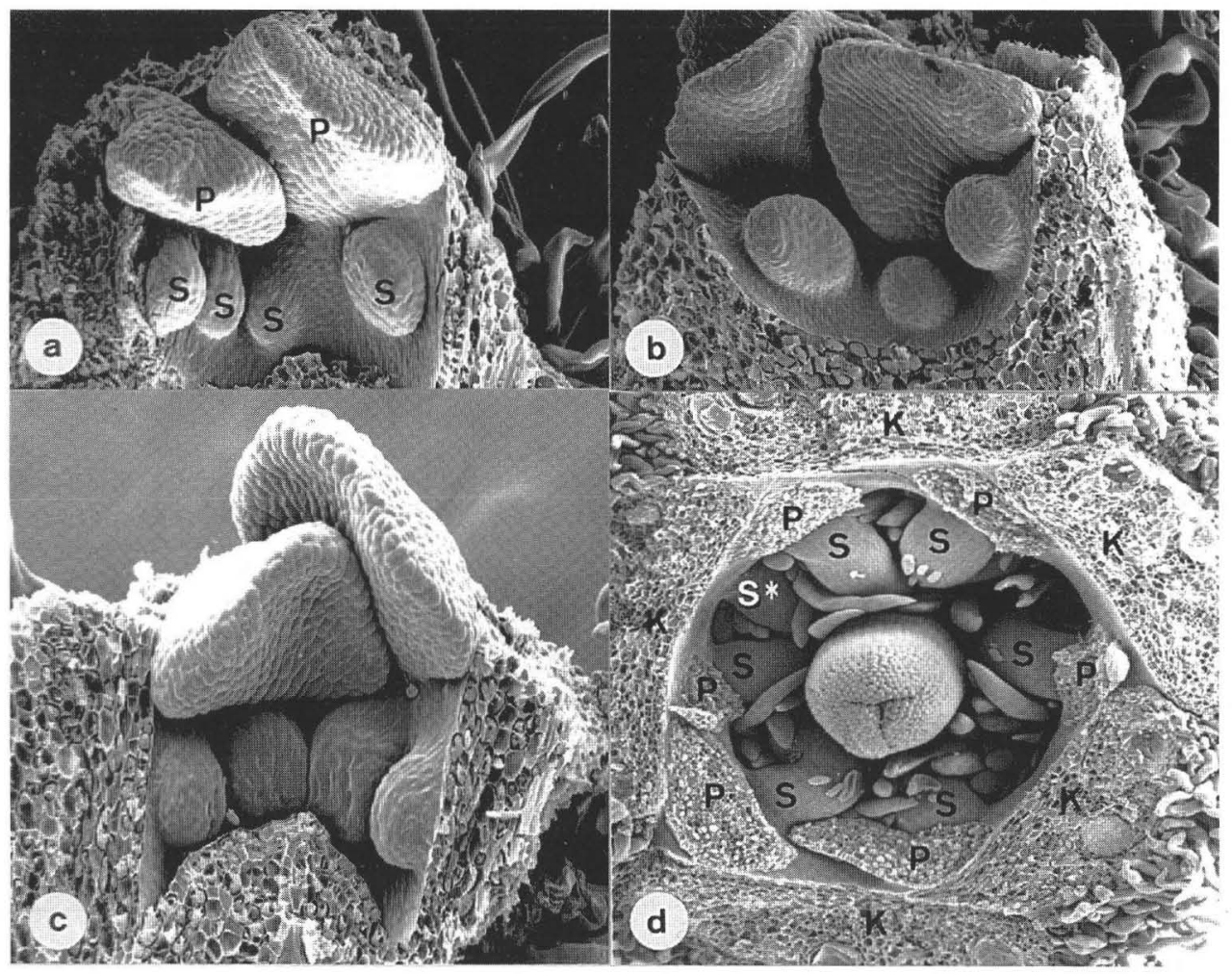

Fig. 21. Floral development of Thaleropia queenslandica. a, part of a flower bud with two petal $(\mathrm{P})$ and four stamen (S) primordia. There is a difference in size between adjacent petals. The stamen primordia are initiated directly on the wall of the hypanthium, not on a swollen PSB $(\times 250) ; \mathbf{b}$, petal and stamen primordia. The older stamens are initiated opposite the petals. The younger stamen is lower down on the hypanthium and is antesepalous $(\times 250)$; c, part of a flower bud illustrating the tight packing of the stamen primordia. The outermost stamen primordia (left and right) are antesepalous and are smaller than the antepetalous stamens in the centre $(\times 285)$; $d$, mature flower bud with five sepals $(K)$ and six petals $(P)$ removed. There is one free stamen $(S)$ in front of each petal and another stamen $\left(\mathrm{S}^{*}\right)$ inserted in an irregular position (× 90). (from DAO 199). 
Because of the spiral phyllotaxy of the petals, and hence the sequential availability of antepetalous regions for pre-staminal bulge initiation, the petal and pre-staminal bulge sizes are not uniform in early flower stages; the first formed petal and prestaminal bulge are significantly larger than those formed last. Initiation of stamen primordia is not synchronous, nor even strictly sequential, around the flower; a number of stamen primordia are initiated on the oldest pre-staminal bulge well before there is any evidence of primordia on the youngest. In terms of the initiation of individual stamen primordia, each pre-staminal bulge is operating as a separate morphogenetic and phyllotactic unit that is independent of other pre-staminal bulges in the flower.

Another characteristic that defines the pre-staminal bulge as a discrete morphological entity that is more than just the collection of its stamens is the fate of the fascicle as the flower enlarges. The increase in the circumference of the hypanthium is largely the result of expansion in the antesepalous regions; the sepals maintain increase in

a

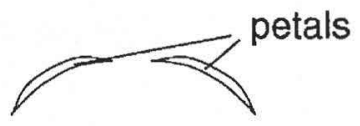

C

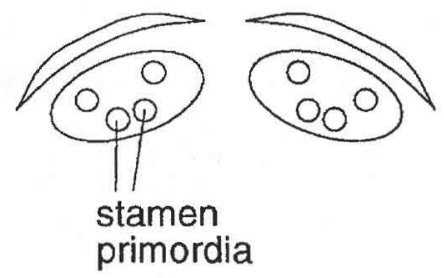

b

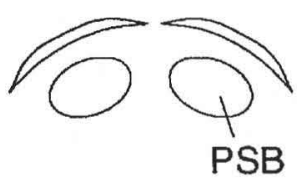

d
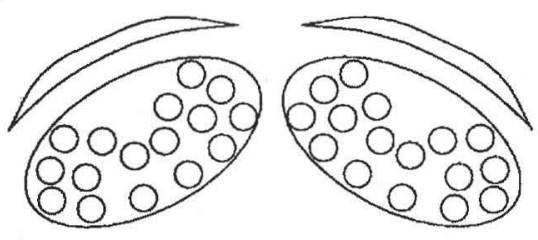

e

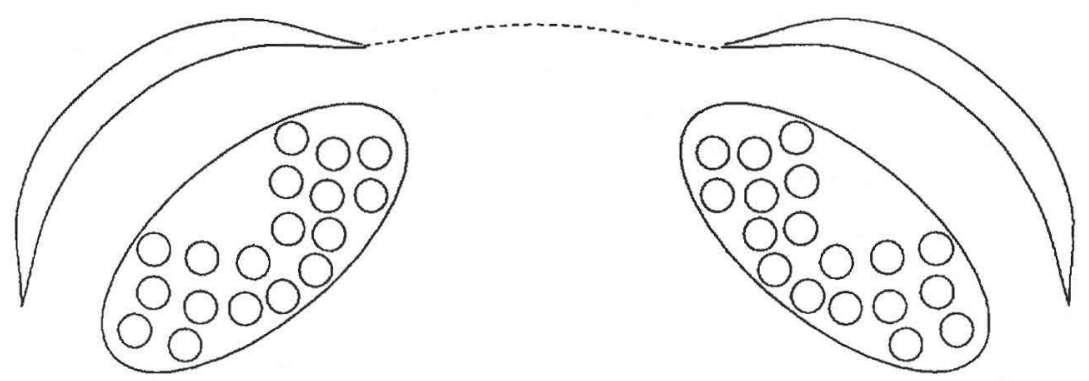

Fig. 22. Diagram illustrating the relationships between PSB formation, stamen initiation and hypanthial expansion in flowers with fascicles formed from a pre-staminal bulge. a, petal primordia; $b$, a pre-staminal bulge (PSB) forms on the floral tube directly centripetal to each petal; c, the PSB has increased in size and stamen primordia are initiated; $\mathbf{d}$, as more stamen primordia are initiated, the PSB increases in size; e, hypanthial expansion in the antesepalous region results in the separation of each bundle of stamens. Subsequent extension of the fused and free parts of the filaments result in the formation of distinct stamen fascicles. 
a<smiles>c1ccccc1</smiles>

b

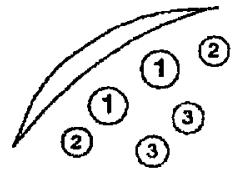

c

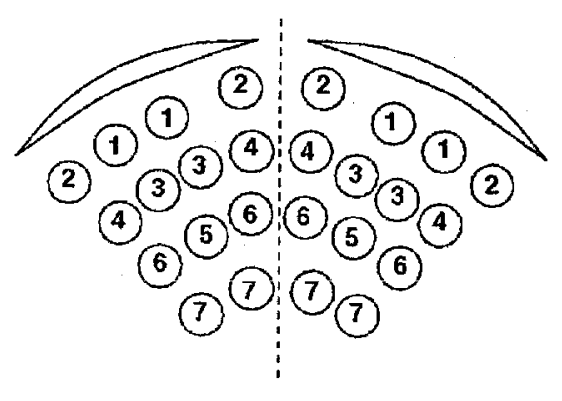

d

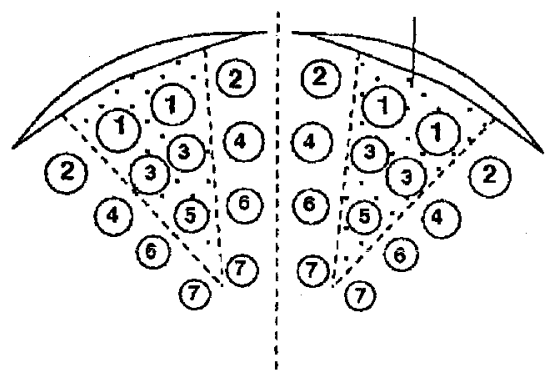

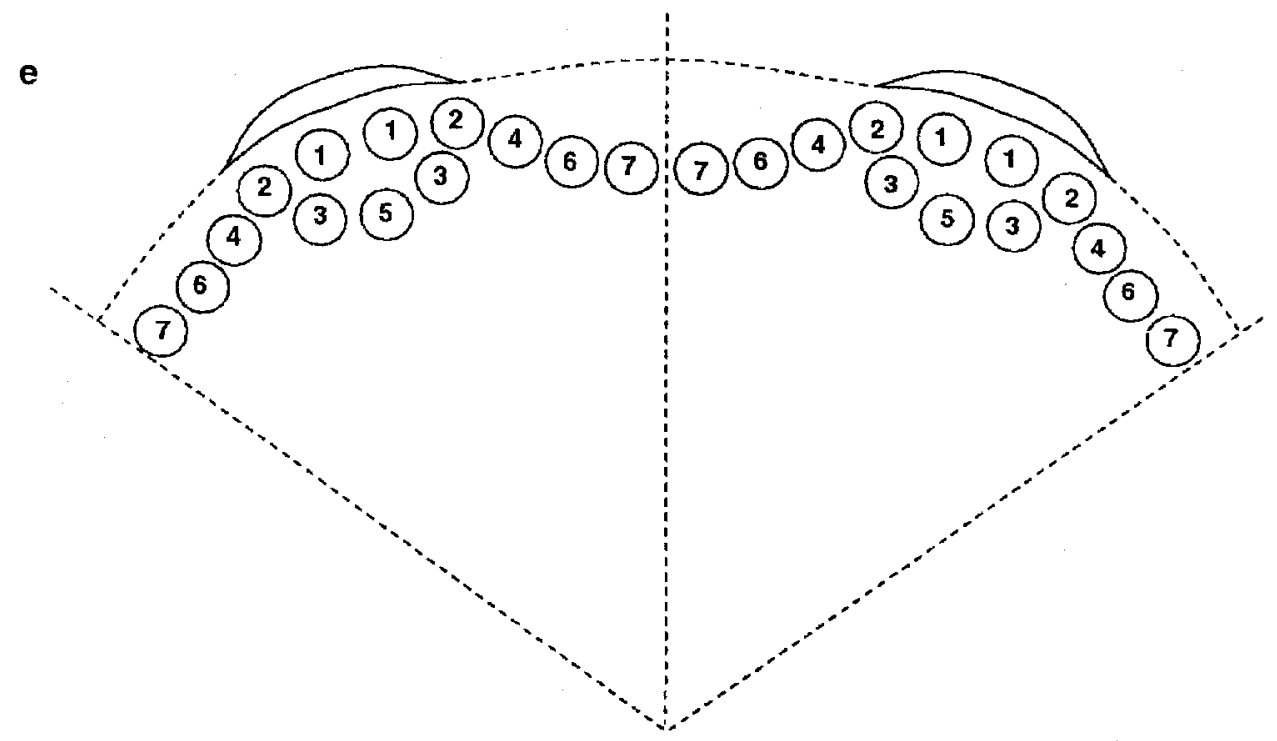

Fig. 23. Diagram illustrating the pattern of stamen initiation and hypanthial expansion in Xanthostemon/Lysicarpus-type flowers. a, stamens are initiated directly on to the floral tube centripetal to the petals; $\mathbf{b}$, expansion and elongation of the floral tube allows more space for the initiation of more stamen primordia; $\mathbf{c}$, numerous stamens may be formed provided there is sufficient space on the floral tube; $d$, expansion of the hypanthium prior to anthesis occurs chiefly in the antesepalous region; $\mathbf{e}$, hypanthial expansion results in the antesepalous stamens being spread out into a single row of more or less evenly spaced filaments whereas the lack of expansion in the antepetalous regions results in there being more than one row. 
width corresponding to the hypanthium, but the petals maintain a narrow zone of insertion on the hypanthial rim. The fascicle of stamens resulting from each prestaminal bulge remains in its antepetalous position, also with a narrow area of insertion; as a consequence the individual fascicles are distantly separated in the mature flower (Fig. 22). The fact that individual stamens remain so tightly clustered, and do not disperse at all with hypanthial expansion, indicates that the stamens are subordinate to the pre-staminal bulge, not to the receptacle of the flower. A similar pattern occurs in Welchiodendron (Fig. 9).

In Tristaniopsis laurina (Fig. 11) the pre-staminal bulges are only just apparent prior to stamen primordia initiation; in fact the whole flower is less developed than at the same stage in $L$. confertus and the petals are also correspondingly smaller. This lesser independent development of the pre-staminal bulge correlates with almost no 'fusion' of stamen filaments in the fascicle, but the fascicles still manifest as discrete units that maintain their restricted area of insertion in the antepetalous regions, each fascicle widely separated from the others in the fully expanded flower.

No pre-staminal bulge develops prior to inception of individual stamen primordia in Xanthostemon and Lysicarpus (Figs 12-16). Instead, two to several stamen primordia form directly on the flank of the apex in positions more or less in front of each petal. The concavity of the apex and the separation of adjacent petals combine to give the impression that the stamen primordia, like the pre-staminal bulge in Lophostemon, form directly on the petal primordia, but there is nothing in the subsequent development of either stamens or petals to suggest they are in any way morphogenetically linked. Subsequent primordia fill in the rest of the concave apex laterally and radially but the grouped appearance remains clearly visible. In X. oppositifolius, they appear superficially to be in triangular, antepetalous groups up to four stamens wide and four tiers deep, but this is an illusion caused largely by the shape of the apex. The cone shape of the inverted apex allows more primordia around the circumference at the top (nearest the petals) than at the bottom (nearest the centre) and this, together with the location of the oldest stamens of each tier in the centres of the antepetalous areas, accentuates the clustering of stamens (Fig. 23a-c). In fact, the stamens form evenly over the ring-shaped flank of the invaginated apex, which acts a single, continuous, phyllotactic zone.

Enlargement of the flower subsequent to organ inception, like Lophostemon, occurs largely by expansion in the antesepalous regions; sepal bases expand correspondingly, but the petals remain attached narrowly. The few stamens in the static zone immediately in front of each petal maintain their position relative to the petal and to each other, resulting in an apparent 'group' two to several stamens deep. The rest are displaced from their multi-tiered positions by expansion of the flower, and more or less evenly spaced out in a single row around the entire rim of the hypanthium. (Fig. 23d,e). This secondary relocation of the stamens is a stark contrast to the determinate fascicles of Lophostemon, Welchiodendron and Tristaniopsis, and indicates that the stamens of Xanthostemon and Lysicarpus are subordinate to the hypanthium or floral axis, and that there is no intervening morphological structure.

Metrosideros collina and Tristania neriifolia (Figs 17-20) have far fewer stamen primordia and not nearly as great an expansion of the hypanthium; these features combine to make their interpretation equivocal. Metrosideros collina shows a hint of pre-staminal bulges, but only one row of stamens forms around the flower. These stamens are spread evenly around the hypanthium at anthesis, but flower expansion is not sufficient to widely space the filaments to allow consideration of the similarity between antepetalous and antesepalous regions. Occasionally there is a small gap opposite a sepal, and sometimes two adjacent stamen primordia become continuous and grow as a single, thick filament, but there is no consistent pattern of clustering, and there is no obvious filament base fusion typical of fascicled taxa. 
The three united stamens opposite each petal in Tristania neriifolia probably reflect the lack of space available at the time of primordia initiation, followed by enough expansion in the antesepalous regions to keep every third pair of stamen primordia separate, but the lack of availability of early ontogenetic stages precludes a definite conclusion. Thaleropia queenslandica (Fig. 21) has even fewer stamens, and these are clearly inserted directly on the flank of the invaginated apex and are evenly and widely separated by subsequent expansion of the flower.

Although the diversity in form of mature flowers can be adequately described in terms of discrete morphological units such as stamen fascicles, this is not always the most appropriate approach for the best understanding of the mechanism of evolutionary change or the circumscription of systematic characters. Flowers, like all morphological structures, are the result of complex ontogenetic processes that have spatial and temporal components. Differences in mature flower structure usually result from differences in ontogeny, and so factors affecting the spatial and temporal relationships of floral organ initiation and development best describe the key events that lead to this diversity.

The genera of Myrtaceae examined here are good examples of this. Lophostemon confertus has a well developed pre-staminal bulge that is quite large, allowing the insertion of in excess of one hundred stamen primordia. However, constriction of the base of the PSB in a static, non-expanding area of the flower does not allow for maintenance of integrity of one hundred expanding stamen primordia, which merge and result in a fascicle of united filaments. The comparatively earlier inception of stamens in Tristaniopsis laurina leads to fewer stamens developing on a smaller prestaminal bulge. The pre-staminal bulge (and antepetalous area) is still enlarging in that critical period when stamen primordia are expanding, so the filaments remain separate and there is little or no common filament tissue in the fascicle. Lophosternon lactifluus is intermediate. The development of the pre-staminal bulge is sufficient to result in a fused fascicle of filaments, but stamen initiation is sufficiently early to prevent a vertical groove in the pre-staminal bulge. Consequently, each fascicle has fewer stamens than L. confertus, and is not cleft. In Xanthostemon and Lysicarpus stamens appear very soon after petals and there is no independent development of a pre-staminal bulge, and no fascicle. If there is insufficient expansion of the flower, especially in early stages, there is no room for more than a few stamens to form, e.g., Tristania neriifolia. Although the morphological differences in mature flowers manifest as variation in number and arrangement of parts, their cause is differences in timing and duration of organ initiation on floral apices growing at different rates.

Because changes in spatial/temporal factors are potentially variable and reversible, evolutionary change from one condition to the other in either direction is possible. If a species has potential to produce a pre-staminal bulge, but this is inhibited by early stamen initiation directly on the apex, then there will be no fascicles. However, a delay in stamen initiation would allow the pre-staminal bulge and fascicles to form (Figs 22, 23). It is a good illustration of how features that are 'potential' by virtue of one aspect of the genotype (i.e., pre-staminal bulge) can be modified by results of another aspect (i.e., timing of stamen initiation). The potential to produce the pre-staminal bulge may not have been lost; it is just precluded by a change in the timing of the ontogenetic processes. A reversion in the timing would allow the prestaminal bulge, and hence fascicles, to manifest again.

The rigid framework of the classical concept of angiosperm flowers as consisting of four successive whorls of organs, i.e., sepals, petals, stamens and carpels, does not provide a category of organ to which an entire fascicle of stamens can be homologised. Consequently, stamen fascicles have usually been interpreted as a modification, both ontogenetic and phylogenetic, of a single stamen (see Leins 1964, 1975). While this 
may be an adequate interpretation for stamen fascicles in some flowers, possibly even for other myrtalean genera such as Lagerstroemia (Lythraceae; Ronse Decraene \& Smets 1991), it does not appear to be particularly appropriate for the genera of Myrtaceae discussed here. The independent development of the pre-staminal bulge prior to stamen initiation, the dissimilarity of its size and shape to typical stamen primordia, the phyllotactic independence of stamens on one pre-staminal bulge from stamens on other pre-staminal bulges, and the maintenance of the resulting fascicle as a discrete unit in the mature flower, predicates the pre-staminal bulge and resulting fascicle as a morphogenetic structure distinct from the other floral organs. A flexible framework of floral construction is needed to allow the recognition, where appropriate, of morphological units in addition to the four classical organ categories; in this case, fascicles resulting from PSBs are a novel feature for these myrtaceous flowers.

According to our interpretation the pre-staminal bulge is not a primary stamen primordium, so it is inappropriate to describe the morphology of these myrtaceous androecia in terms of conventional haplostemony/diplostemony. Haplostemony and diplostemony are simply the results of certain spatial and temporal factors that determine the positions of petals and stamens in a regular, consistent, acropetal phyllotaxy, directly on a usually convex floral meristem. They are not architectural groundplans to which patterns of all flowers must conform, nor immutable types of which all flowers must be avatars. If the spatial and temporal relations change, then so will the morphology and phyllotaxy of the flower, and there is no need to invoke a direct correspondence between every organ and positional relationship in such different flowers. Although the plesiomorphic condition for Myrtaceae may well be diplostemonous (Schmid 1980, Ronse Decraene \& Smets 1991), with subsequent changes to apparent obdiplostemonous, haplostemonous and obhaplostemonous conditions in some taxa (Johnson \& Briggs 1984), it is not really appropriate to describe flowers such as Lophostemon, Tristaniopsis, Xanthostemon and Lysicarpus as modifications of these conditions. These flowers, with their deeply concave apical meristems and non-acropetal order of floral parts, have different spatial and temporal parameters to (ob)haplostemonous and (ob)diplostemonous flowers, and they manifest with a different form and phyllotaxy. The antepetalous fascicles of stamens exhibited by Lophostemon, Welchiodendron and Tristaniopsis represent a special type of polyandry; it is not complex obhaplostemony sensu Ronse Decraene \& Smets, because each fascicle does not result from the proliferation of a single stamen primordium. Similarly, in Xanthostemon and Lysicarpus polyandry results from the prolonged inception on the floral apex of numerous individual stamen primordia, not the proliferation of a few antepetalous or antesepalous precursors. In fact the term proliferation, which is used by Ronse Decraene \& Smets (1991) and Johnson \& Briggs (1984) to explain both of these polyandrous conditions, is best avoided in these instances. In both Lophostemon and Xanthostemon, polyandry is beyond the concepts of haplostemony and diplostemony in both their ontogenetic and phylogenetic senses.

\section{Acknowledgements}

For collecting specimens used in this study, we thank Peter Wilson, Royal Botanic Gardens Sydney; Richard Johnson, Royal Botanic Gardens, Mount Annan; Ian Smith, Maranoa Gardens, Melbourne; Gregor Calvert and Chris Roberts, Pajinka Wilderness Lodge, Queensland; Bernie Hyland, Tropical Forest Research Centre, Atherton, Queensland; Anthony Vadala, The University of Melbourne; Peter Neish, Royal Botanic Gardens, Melbourne and Andrew Rozefelds, Tasmanian Herbarium, Hobart. 
We thank the directors of NSW and UNSW for gifts of spirit material, QRS for permitting loans of spirit material and Professor Carrick Chambers (NSW) for permitting the collection of plant material from RBG Sydney and RBG Mount Annan. Financial support was received from Australian Research Council grant A19131815 to AND and PYL.

\section{References}

Briggs, B.G. \& Johnson, L.A.S. (1979) Evolution in the Myrtaceae - Evidence from inflorescence structure. Proceedings of the Linnean Society of New South Wales 102: 157-256.

Bunniger, L. (1972) Untersuchungen über die morphologische Natur des Hypanthiums bei Myrtalesund Thymelaeales-Familien. II. Myrtaceae. III. Vergleich mit den Thymelaeaceae. Beiträge zur Biologie der Pflanzen 48: 79-156.

Drinnan, A.N. \& Ladiges, P.Y.L. (1988) Perianth development in Angophora and the bloodwood eucalypts (Myrtaceae). Plant Systematics and Evolution 160: 219-239.

Drinnan, A.N. \& Ladiges, P.Y.L. (1989a) Operculum development in the Eudesmiene B eucalypts and Eucalyptus caesia (Myrtaceae). Plant Systematics and Evolution 165: 227-237.

Drinnan, A.N. \& Ladiges, P.Y.L. (1989b) Corolla and androecium development in some Eudesmia eucalypts (Myrtaceae). Plant Systematics and Evolution 165: 239-254.

Drinnan, A.N. \& Ladiges, P.Y.L. (1989c) Operculum development in Eucalyptus cloeziana and Eucalyptus informal subg. Monocalyptus (Myrtaceae). Plant Systematics and Evolution 166: 183-196.

Drinnan, A.N. \& Ladiges, P.Y.L. (1991a) Floral development and systematic position of Eucalyptus curtisii (Myrtaceae). Australian Systematic Botany 4: 539-551.

Drinnan, A.N. \& Ladiges, P.Y.L. (1991b) Floral development in the 'Symphyomyrtus group' of eucalypts (Eucalyptus: Myrtaceae). Australian Systematic Botany 4: 553-562.

Johnson, L.A.S. \& Briggs, B.G. (1984) Myrtales and Myrtaceae - A phylogenetic analysis. Annals of the Missouri Botanical Garden 71: 700-756.

Leins, P. (1964) Das zentripetale und zentrifugale Androeceum. Berichte der Deutschen Botanischen Gesellschaft 77: 23-25.

Leins, P. (1965) Die inflorescenz und frühe blütenentwicklung von Melaleuca nesophila F. Muell. (Myrtaceae). Planta 65: 195-204.

Leins, P. (1975) Die Beziehungen zwischen multistaminaten und einfachen Androeceen. Botanische Jahrbücher für Systematik 96: 231-237.

Mayr, B. (1969) Ontogenetische Studien an Myrtales-Blüten. Botanische Jahrbücher für Systematik 89: $210-271$.

O'Brien, T.P. \& McCully, M.E. (1981) The Study of Plant Structure: Principles and Selected Methods (Termarcarphi: Melbourne).

Payer, J.-B. (1857) Traité D'organogénie Comparée de la Fleur. (Victor Masson: Paris).

Ronse Decraene, L.P. \& Smets, E.K. (1991) The impact of receptacular growth on polyandry in the Myrtales. Botanical Journal of the Linnean Society 105: 257-269.

Schmid, R. (1980) Comparative anatomy and morphology of Psiloxylon and Heteropyxis, and the subfamilial and tribal classification of Myrtaceae. Taxon 29:559-595. 